\title{
Horizontal Innovation in the Theory of Growth and Development.*
}

\author{
Gino Gancia ${ }^{\dagger}$ and Fabrizio Zilibotti ${ }^{\ddagger}$
}

January 31, 2005

\begin{abstract}
We analyze recent contributions to growth theory based on the model of expanding variety of Romer (1990). In the first part, we present different versions of the benchmark linear model with imperfect competition. These include the "labequipment" model, "labor-for-intermediates" and "directed technical change". We review applications of the expanding variety framework to the analysis of international technology diffusion, trade, cross-country productivity differences, financial development and fluctuations. In many such applications, a key role is played by complementarities in the process of innovation.

JEL Numbers: D92, E32, F12, F15, F43, G22, O11, O16, O31, O33, O41, O47.

Keywords: appropriate technology, complementarity, cycles, convergence, directed technical change, endogenous growth, expanding variety, financial development, imperfect competition, integration, innovation, intellectual property rights, imitation, knowledge, learning, patents, technical change, trade, traps.
\end{abstract}

\section{IntRoduCtion}

Endogenous growth theory formalizes the role of technical progress in explaining modern economic growth. Although this is a relatively recent development, many of its ideas were already stressed by authors such as Kuznets, Griliches, Schmookler, Rosenberg and Schumpeter. During the 1950s and 1960s, mainstream economics was dominated by the one-sector neoclassical growth model of Solow (1956) and Swan (1956), whose main focus was on capital accumulation. The model postulated the existence of an aggregate production function featuring constant returns to scale and returns to each input falling

* Paper prepared for the Handbook of Economic Growth (eds: Philippe Aghion and Steve Durlauf). We thank Philippe Aghion, Jeremy Greenwood, Kiminori Matsuyama and Jerome Vandennbusche for helpful comments, Zheng Song for excellent research assistance, and Christina Lönnblad for editorial assistance.

†CREI and Universitat Pompeu Fabra

${ }^{\ddagger}$ Institute for International Economic Studies, Stockholm University. 
asymptotically to zero; given that some inputs cannot be accumulated, the model could not generate sustained growth unless technology was assumed to improve exogenously. This simple treatment of technology as exogenous was considered as unsatisfactory for two main reasons: first, by placing the source of sustained growth outside the model, the theory could not explain the determinants of long-run economic performance and second, empirical evidence pointed out that technical progress often depends on deliberate economic decisions.

The first attempts to endogenize the rate of technical change addressed the first, but not the second, problem. Assuming technical progress to be an unintentional by-product of the introduction of new capital goods through a process named "learning-by-doing", Arrow (1962) was able to generate sustained growth at a rate that depended on investment decisions. Attempts at explicitly modeling investment in innovation faced another difficulty. A replication argument suggests that, for a given state of technology, production functions should exhibit constant returns to scale. If technical progress is considered as an additional input, however, the technology features increasing returns to scale and inputs cannot be paid their marginal product. Models of learning-by-doing avoided the problem by assuming that increasing returns were external to firms, thereby preserving perfect competition. However, this approach is not viable once investment in technology is recognized as intentional. The solution was to follow the view of Schumpeter (1942), that new technologies provide market power and that investment in innovation is motivated by the prospect of future profits. In this spirit, Shell (1973) studied the case of a single monopolist investing in technical change and Nordhaus (1969a) wrote a growth model with patents, monopoly power and many firms. In neither case did the equilibrium feature sustained growth. ${ }^{1}$

A tractable model of imperfect competition under general equilibrium was not available until the analysis of monopolistic competition in consumption goods by Dixit and Stiglitz (1977), later extended to differentiated inputs in production by Ethier (1982). These models also showed how increasing returns could arise from an expansion in the number of varieties of producer and consumer goods, an idea that is at the core of the models studied in this Chapter. The first dynamic models of economic growth with monopolistic competition and innovation motivated by profits were built by Judd (1985) and Grossman and Helpman (1989). Yet, these authors were interested in aspects other than endogenous growth and none of their models featured long-run growth. Romer (1987), who formalized an old idea of Young (1928), was the first to show that models of monopolistic competition could generate long-run growth through the increased specialization of labor across an increasing range of activities. The final step was taken in Romer (1990), which assumed that inventing new goods is a deliberate costly activity and that monopoly profits, granted to innovators by patents, motivate discoveries. Since then, the basic model of endogenous growth with an expanding variety of products has been extended in many direction.

The distinctive feature of the models discussed in this Chapter is "horizontal innovation": a discovery consists of the technical knowledge required to manufacture a new

\footnotetext{
${ }^{1}$ See Levhari and Sheshinski (1969) on necessary and sufficient conditions for the existence of steadystate growth in the presence of increasing returns to scale.
} 
good that does not displace existing ones. Therefore, innovation takes the form of an expansion in the variety of available products. The underlying assumption is that the availability of more goods, either for final consumption or as intermediate inputs, raises the material well-being of people. This can occur through various channels. Consumers may value variety per se. For example, having a TV set and a Hi-Fi yields more utility than having two units of any one of them. Productivity in manufacturing may increase with the availability of a larger set of intermediate tools, such as hammers, trucks, computers and so on. Similarly, specialization of labor across an increasing variety of activities, as in the celebrated Adam Smith example of the pin factory, can make aggregate production more efficient. The main alternative approach is to model innovation as quality improvements on a given array of products ("vertical innovation"), so that technical progress makes existing products obsolete. This process of "creative destruction" was emphasized by Schumpeter and has been formalized in Aghion and Howitt (1992), Grossman and Helpman (1991) and Segerstrom et al. (1991). The two approaches naturally complement each other. The main advantage of models with horizontal innovation lies in their analytical tractability, making them powerful tools for addressing a wide range of questions. However, because of their simplistic view on the interaction between innovators, these models are less suited to studying the effects of competition between "leaders" and "follower" on the growth process.

The first section of this chapter describes a simplified version of Romer (1990) and some extensions used in the literature. The model exhibits increasing returns to scale and steady-state endogenous growth in output per capita and the stock of knowledge. The key feature of the theory is the emphasis on investments in technical knowledge as the determinant of long-run economic growth. Ideas and technological improvements differ from other physical assets, because they entail important public good elements. Inventing new technology is typically costly, while reproducing ideas is relatively inexpensive. Therefore, technical knowledge is described as a non-rival good. Nevertheless, firms are willing to invest in innovation because there exists a system of intellectual property rights (patents) guaranteeing innovators monopoly power over the production and sales of particular goods.

Growth models with an expanding variety of products are a natural dynamic counterpart to trade models based on increasing returns and product differentiation. As such, they offer a simple framework for studying the effects of market integration on growth and other issues in dynamic trade theory. This is the subject of the second section, which shows how trade integration can produce both static gains, by providing access to foreign varieties, and dynamic gains, by raising the rate at which new goods are introduced. Product-cycle trade and imitation are also considered.

In many instances, technical progress may be non-neutral towards different factors or sectors. This possibility is considered in the third section, where biased technical change is incorporated in the basic growth model. By introducing several factors and sectors, the economic incentives to develop technologies complementing a specific factor, such as skilled workers, can be studied. These incentives critically depend on the definition of property rights over the production of new ideas. The high variability in the effectiveness of patent laws across countries has important bearings on the form of 
technical progress. In particular, governments in less developed countries may have an incentive not to enforce intellectual property rights in order to speed up the process of technology adoption. However, the undesired side effect of free-riding is that innovators in industrialized countries lose incentives to create improvements that are most useful in developing countries, but of limited application in industrialized markets.

Section four introduces complementarity in innovation. While innovation has no effect on the profitability of existing intermediate firms in the benchmark model, in reality new technologies can substitute or complement existing technologies. Innovation may cause technological obsolescence of previous technologies, as emphasized by Schumpeterian models. In other cases, new technologies complement rather than substitute the old ones. For instance, the market for a particular technology tends to be small at the time of its introduction, but grows as new compatible applications are developed. This complementarity in innovation can lead to multiple equilibria and poverty traps.

Complementarities in the growth process may also arise from financial markets, as suggested in section five. The progressive endogenous enrichment of asset markets, associated with the development of new intermediate industries, may improve the diversification opportunities available to investors. This, in turn, makes savers more prepared to invest in high-productivity risky industries, thereby fostering further industrial and financial development. As a result, countries at early stages of development go through periods of slow and highly volatile growth, eventually followed by a take-off with financial deepening and steady growth.

Finally, the last section of the Chapter shows how models with technological complementarities can generate rich long-run dynamics, including endogenous fluctuations between periods of high and low growth. Cycles in innovation and growth can either be due to expectational indeterminacy, or the deterministic dynamics of two-sector models with an endogenous market structure.

\section{Growth with Expanding Variety}

In this section, we present the benchmark model of endogenous growth with expanding variety, and some extensions that will be developed in the following sections.

\subsection{The Benchmark Model}

The benchmark model is a simplified version of Romer (1990), where, for simplicity, we abstract from investments in physical capital. The economy is populated by infinitely lived agents who derive utility from consumption and supply inelastic labor. The population is constant, and equal to L. Agents' preferences are represented by an isoelastic utility function:

$$
U=\int_{0}^{\infty} e^{-\rho t} \frac{C_{t}^{1-\theta}-1}{1-\theta} d t
$$

The representative household sets a consumption plan to maximize utility, subject to an intertemporal budget constraint and a No-Ponzi game condition. The consumption 
plan satisfies a standard Euler equation:

$$
\dot{C}_{t}=\frac{r_{t}-\rho}{\theta} \cdot C_{t}
$$

There is no physical capital, and savings are used to finance innovative investments.

The production side of the economy consists of two sectors of activity: a competitive sector producing a homogenous final good, and a non-competitive sector producing differentiated intermediate goods. The final-good sector employs labor and a set of intermediate goods as inputs. The technology for producing final goods is represented by the following production function:

$$
Y_{t}=L_{y, t}^{1-\alpha} \int_{0}^{A_{t}} x_{j, t}^{\alpha} d j,
$$

where $x_{j}$ is the quantity of the intermediate good $j, A_{t}$ is the measure of intermediate goods available at $t, L_{y}$ is labor and $\alpha \in(0,1)$. This specification follows Spence (1976), Dixit and Stiglitz (1977) and Ethier (1982). It describes different inputs as imperfect substitutes, which symmetrically enter the production function, implying that no intermediate good is intrinsically better or worse than any other, irrespective of the time of introduction. The marginal product of each input is decreasing, and independent of the measure of intermediate goods, $A_{t}$.

The intermediate good sector consists of monopolistically competitive firms, each producing a differentiated variety $j$. Technology is symmetric across varieties: the production of one unit of intermediate good requires one unit of final good, assumed to be the numeraire. ${ }^{2}$ In addition, each intermediate producer is subject to a sunk cost to design a new intermediate input variety. New designs are produced instantaneously and with no uncertainty. The innovating firm can patent the design, and acquire a perpetual monopoly power over the production of the corresponding input.

In the absence of intellectual property rights, free-riding would prevent any innovative activity. If firms could costlessly copy the design, competition would drive ex-post rents to zero. Then, no firms would have an incentive, ex-ante, to pay a sunk cost to design a new input.

The research activity only uses labor. An important assumption is that innovation generates an intertemporal externality. In particular, the design of a (unit measure of) new intermediate good requires a labor input equal to $1 /\left(\delta A_{t}\right)$. The assumption that labor productivity increases with the stock of knowledge, $A_{t}$, can be rationalized by the idea of researchers benefitting from accessing the stock of applications for patents, thereby obtaining inspiration for new designs.

The law of motion of technical knowledge can be written as:

$$
\dot{A}_{t}=\delta A_{t} L_{x, t}
$$

\footnotetext{
${ }^{2}$ In Romer (1990), the variable input is physical capital, and the economy has two state variables, i.e., physical capital and knowledge.
} 
where $\delta$ is a parameter and $L_{x}$ denotes the aggregate employment in research. The rate of technological change is a linear function of total employment in research. ${ }^{3}$ Finally, feasibility requires that $L \geq L_{x, t}+L_{y, t}$.

First, we characterize the equilibrium in the final good sector. Let $w$ denote the wage, and $p_{j}$ be the price of the $j$ 'th variety of intermediate input. The price of the final product is the numeraire. The representative firm in the competitive final sector takes prices as parametric and chooses production and technology so as to maximizes profit, given by:

$$
\pi_{t}^{Y}=L_{y, t}^{1-\alpha} \int_{0}^{A_{t}} x_{j, t}{ }^{\alpha} d j-w_{t} L_{y, t}-\int_{0}^{A_{t}} p_{j, t} x_{j, t} d j .
$$

The first-order conditions yield the following factor demands:

$$
p_{j, t}=\alpha L_{y, t}^{1-\alpha} x_{j, t}^{\alpha-1} \quad \forall j \in\left[0, A_{t}\right]
$$

and

$$
w_{y, t}=(1-\alpha) L_{y, t}^{-\alpha} \int_{0}^{A_{t}} x_{j, t}^{\alpha} d j
$$

Next, consider the problem of intermediate producers. A firm owning a patent sets its production level so as to maximize the profit, subject to the demand function (6). The profit of the firm producing the $j$-th variety is $\pi_{j, t}=p_{j, t} x_{j, t}-x_{j, t}$. The optimal quantity and price set by the monopolist are:

$$
x_{j, t}=x_{t}=\alpha^{\frac{2}{1-\alpha}} L_{y, t} \text { and } p_{j, t}=p=1 / \alpha,
$$

respectively. Hence, the maximum profit for an intermediate producer is:

$$
\pi_{j, t}=\pi_{t}=(p-1) x_{t}=\frac{1-\alpha}{\alpha} \alpha^{\frac{2}{1-\alpha}} L_{y, t} .
$$

Substitution of $x_{t}$ into (7) yields the equilibrium wage as:

$$
w_{t}=(1-\alpha) \alpha^{\frac{2 \alpha}{1-\alpha}} A_{t} .
$$

Next, we guess-and-verify the existence of a balanced growth (BG) equilibrium, such that consumption, production and technical knowledge grow at the same constant rate, $\gamma$, and the two sectors employ constant proportions of the workforce. ${ }^{4}$ In BG, both the

${ }^{3}$ Jones (1995) generalizes this technology and lets

$$
\dot{A}_{t}=\delta A_{t}^{\gamma_{a}} L_{x, t}^{\left(1-\gamma_{L}\right)},
$$

where $\gamma_{A} \leq 1$ is a positive externality through the stock of knowledge and $\gamma_{L}$ is a negative externality that can be interpreted as coming from the duplication of research effort. Assuming $\gamma_{A}<1$ leads to qualitative differences in the prediction of the model. In particular, the specification where $\gamma_{A}=1$ and $\gamma_{L}=0$, which is the model discussed here, generates scale effects. See further discussion later in this chapter and, especially, in chapter ... of this Handbook.

${ }^{4}$ The equilibrium that we characterized can be proved to be unique. Moreover, the version of Romer's model described here features no transitional dynamics, as in $A K$ models (Rebelo, 1991). 
production and the profits of intermediate firms, as given by equations (8) and (9), are constant over time and across industries. Thus, $x_{t}=x$ and $\pi_{t}=\pi$.

Free entry implies that the present discounted value (PDV) of profits from innovation cannot exceed the entry cost. By the Euler equation, (2), the interest rate is also constant in BG. Hence, the PDV of profits equals $\pi / r$. The entry cost is given by the wage paid to researchers, i.e., $w_{t} /\left(\delta A_{t}\right)$. Therefore, the free entry condition can be written as:

$$
\frac{\pi}{r} \leq \frac{w_{t}}{\delta A_{t}}
$$

We can then use (9) and (10), and substitute the expressions of $\pi$ and $w_{t}$ into (11):

$$
\frac{\left(\frac{1-\alpha}{\alpha}\right) \alpha^{\frac{2}{1-\alpha}} L_{y}}{r} \leq \frac{(1-\alpha) \alpha^{\frac{2 \alpha}{1-\alpha}}}{\delta} .
$$

The right hand-side expression is the marginal cost of innovation, independent of $A_{t}$, due to the cancellation of two opposite effects. On the one hand, labor productivity and, hence, the equilibrium wage grow linearly with $A_{t}$. On the other hand, the productivity of researchers increases with $A_{t}$, due to the intertemporal knowledge spillover. Thus, the unit cost of innovation is constant over time. Note that, without the externality, the cost of innovation would grow over time, and technical progress and growth would come to a halt, like in the neoclassical model.

For innovation to be positive, (12) must hold with equality. We can use (i) the resource constraint, implying that $L_{y}=L-L_{x}$ and (ii) the fact that, from (4) and BG, $L_{x}=\gamma / \delta$, to express (12) as a relationship between the interest rate and the growth rate:

$$
r=\alpha(\delta L-\gamma) .
$$

(13) describes the equilibrium condition on the production side of the economy: the higher is the interest rate that firms must pay to finance innovation expenditure, the lower is employment in research and growth.

Finally, the consumption Euler equation, (2), given BG, yields:

$$
r=\rho+\theta \gamma,
$$

which is the usual positive relation between interest rate and growth. Figure 1 plots the linear equations (13) and (14), which characterize the equilibrium. The two equations correspond, respectively, to the DD (demand for funds) and SS (supply of savings) linear schedules.

\section{FIGURE 1}


An interior solution exists if and only if $\alpha \delta L>\rho$. When this condition fails to be satisfied, all workers are employed in the production of consumption goods. When it is positive, the equilibrium growth rate is

$$
\gamma=\frac{\delta \alpha L-\rho}{\alpha+\theta}
$$

showing that the growth rate is increasing in the productivity of the research sector $(\delta)$, the size of the labor force $(L)$ and the intertemporal elasticity of substitution of consumption $(1 / \theta)$, while it is decreasing in the elasticity of final output to labor, $(1-\alpha)$, and the discount rate.

The trade-off between final production (consumption), on the one hand, and innovation and growth, on the other hand, can be shown by substituting the equilibrium expression of $x$ into the aggregate production function, (3). This yields:

$$
Y_{t}=\alpha^{\frac{2 \alpha}{1-\alpha}} L_{y} A_{t}=\alpha^{\frac{2 \alpha}{1-\alpha}}(L-\gamma / \delta) A_{t} .
$$

The decentralized equilibrium is inefficient for two reasons: ${ }^{5}$

1. Intermediate firms exert monopoly power, and charge a price in excess of the marginal cost of production. This leads to an underproduction of each variety of intermediate goods.

2. the accumulation of ideas produces externalities not internalized in the laissez-faire economy. Innovating firms compare the private cost of innovation, $w_{t} /\left(\delta A_{t}\right)$, with the present discounted value of profits, $\pi / r$. However, they ignore the spillover on the future productivity of innovation.

Contrary to Schumpeterian models, innovation does not cause "creative destruction", i.e., no rent is reduced by the entry of new firms. As a result, growth is always suboptimally low in the laissez-faire equilibrium. Policies aimed at increasing research activities (e.g., through subsidies to R\&D or intermediate production) are both growthand welfare-enhancing. This result is not robust, however. Benassy (1998) shows that in a model where the return to specialization is allowed to vary and does not depend on firms' market power $(\alpha)$, research and growth in the laissez-faire equilibrium may be suboptimally too high.

\subsection{Two Variations of the Benchmark Model: "Lab-Equipment" and "LABOR-FOR INTERMEDIATES"}

We now consider two alternative specifications of the model that have been used in the literature, and that will be discussed in the following sections. The first specification

\footnotetext{
${ }^{5}$ There is an additional reason why, in general, models with a Dixit-Stiglitz technology can generate inefficient allocations in laissez-faire, namely that the range of intermediate goods produced is endogenous. The standard assumption of complete markets is violated in Dixit-Stiglitz models, because there is no market price for the goods not produced. This issue is discussed in Matsuyama (1995, 1997). A dynamic example of such a failure is provided by the model of Acemoglu and Zilibotti (1997), which is discussed in detail in section 6 .
} 
is the so-called "lab-equipment" model, where the research activity uses final output instead of labor as a productive input. ${ }^{6}$ More formally, equation (4) is replaced by the condition $\dot{A}_{t}=Y_{x} / \mu$, where $Y_{x}$ denotes the units of final output devoted to research (hence, consumption is $C=Y-A x-Y_{x}$ ) and $\mu$ the output cost per unit of innovation. In the lab-equipment model, there is no research spillover of the type discussed in the benchmark model. Labor is entirely allocated to final production $\left(L_{y}=L\right)$, and the free-entry condition (12) is replaced by

$$
\frac{\left(\frac{1-\alpha}{\alpha}\right) \alpha^{\frac{2}{1-\alpha}} L}{r} \leq \mu
$$

Hence, using the Euler condition, (14), we obtain the following equilibrium growth rate:

$$
\gamma=\left((1-\alpha) \alpha^{\frac{1+\alpha}{1-\alpha}} L / \mu-\rho\right) / \theta
$$

Sustained growth is attained by allocating a constant share of production to finance the research activity.

The second specification assumes that labor is not used in final production, but is used (instead of final output) as the unique input in the intermediate goods production. ${ }^{7}$ More formally, the final production technology is

$$
Y_{t}=Z^{1-\alpha} \int_{0}^{A_{t}} x_{j, t}^{\alpha} d j
$$

where $Z$ is a fixed factor (e.g., land) that is typically normalized to unity and ignored. In this model, $1 / A_{t}$ units of labor are required to produce one unit of any intermediate input, with constant marginal costs. Therefore, in this version of the model, innovation generates a spillover on the productivity of both research and intermediate production. ${ }^{8}$ We refer to this version as the "labor-for-intermediates" model.

It immediately follows that, in equilibrium, the production of each intermediate firm equals $x=L-L_{x}$. The price of intermediates is once more a mark-up over the marginal cost, $p_{t}=w_{t} /\left(\alpha A_{t}\right)$. In a BG equilibrium, wages and technology grow at the same rate, hence their ratio is constant. Let $\omega \equiv\left(w_{t} / A_{t}\right)$. The maximum profit is, then:

$$
\pi=\left(\frac{1-\alpha}{\alpha}\right) \omega x=\frac{1-\alpha}{\alpha} \omega\left(L-L_{x}\right)
$$

\footnotetext{
${ }^{6}$ The "lab-equipment" model was first introduced by Romer and Rivera Batiz (1991a); see also Barro and Sala-i-Martin (1995).

${ }^{7}$ We follow the specification used by Young (1993). A related approach, treating the variety of inputs as consumption goods produced with labor, is examined in Grossman and Helpman (1991).

${ }^{8}$ The spillover on the productivity of intermediate production is not necessary to have endogenous growth. Without it, an equilibrium can be found in which production of each intermediate falls as $A$ grows: $\gamma_{A}=-\gamma_{x}$. In this case, employment in production, $A x$, is constant and the growth rate of $Y$ is $(1-\alpha) \gamma_{A}$.
} 
The free entry condition can be expressed as:

$$
\frac{1-\alpha}{r \alpha}\left(L-L_{x}\right) \leq \frac{1}{\delta}
$$

hence,

$$
\gamma=\left(\frac{1-\alpha}{\alpha} L \delta-\rho\right) /\left(\frac{1-\alpha}{\alpha}+\theta\right)
$$

Clearly, both the "lab-equipment" and "labor-for-intermediates" model yield solutions qualitatively similar to that of the benchmark model.

\subsection{Limited Patent Protection}

In this section, we discuss the effects of limited patent protection. For simplicity, we focus on the lab-equipment version discussed in the previous section. The expectation of monopoly profits provides the basic incentive motivating investment in innovation; at the same time, monopoly rights introduce a distortion in the economy that raises prices above marginal costs and causes the underprovision of goods. Since the growth rate of knowledge in the typical decentralized equilibrium is below the social optimum, the presence of monopoly power poses a trade-off between dynamic and static efficiency, leading to the question, first studied by Nordhaus (1969), of whether there exists an optimal level of protection of monopoly rights. In the basic model, we assumed the monopoly power of innovators to last forever. Now, we study how the main results change when agents cannot be perfectly excluded from using advances discovered by others. A tractable way of doing this is to assume monopoly power to be eroded at a constant rate, so that in every instant, a fraction $m$ of the monopolized goods becomes competitive. ${ }^{9}$ Then, for a given range of varieties in the economy, $A_{t}$, the number of "imitated" intermediates that have become competitive, $A_{t}^{*}$, follows the law of motion:

$$
\dot{A}_{t}^{*}=m\left(A_{t}-A_{t}^{*}\right)
$$

Stronger patent protection can be considered as a reduction in the imitation rate $m$. Note that the model now has two state variables, $A_{t}$ and $A_{t}^{*}$, and will exhibit transitional dynamics. In general, from any starting point, the ratio $A_{t}^{*} / A_{t}$ will converge to the steady-state level: ${ }^{10}$

$$
\frac{A^{*}}{A}=\frac{m}{\gamma+m}
$$

where $\gamma \equiv \dot{A} / A$.

Once a product is imitated, the monopoly power of the original producer is lost and its prices is driven down to the marginal cost by competition. Thus, at each point in

\footnotetext{
${ }^{9} \mathrm{~A}$ growth model with limited patent life is developed by Judd (1985). Here, we follow Barro and Sala-i-Martin (1995). An alternative way of introducing limited patent protection is to assume monopolies to have a deterministic lifetime $T$. In this case, the PDV of an innovation is $\left(1-e^{-r T}\right) \pi / r$ (assuming balanced growth).

${ }^{10}$ This can be seen imposing $\dot{A}^{*} / A^{*}=\gamma$ in (19).
} 
time, intermediates still produced by monopolists are sold as before at the markup price $1 / \alpha$, while for the others, the competitive price is one. Substituting prices into demand functions yields the quantity of each intermediate sold in equilibrium:

$$
\begin{aligned}
& x_{j}=\alpha^{1 /(1-\alpha)} L \equiv x^{*} \quad \text { for } j \in\left(0, A_{t}^{*}\right) \\
& x_{j}=\alpha^{2 /(1-\alpha)} L \equiv x \quad \text { for } j \in\left(A_{t}^{*}, A_{t}\right) .
\end{aligned}
$$

Note that $x^{*}>x$, because the monopolized goods have a higher price.

Free entry requires the PDV of profits generated by an innovation, $V$, to equal its cost $\mu$. Along the balanced growth path, where the interest rate is constant, arbitrage in asset markets requires the instantaneous return to innovation, $\pi / \mu$, to equal the real interest rate adjusted for imitation risk: $r+m .{ }^{11}$ Since prices and quantities of the monopolized goods are identical to those in the basic model, $\pi$ is not affected by imitation. Imitation only affects the duration of the profit flow, which is reflected in the effective interest rate. Therefore, limiting patent lives introduces a new inefficiency: although the benefit from a discovery is permanent for the economy, the reward for the innovator is now only temporary. Using the Euler equation for consumption growth, $\gamma=(r-\rho) / \theta$, and the adjusted interest rate in (17), we get the growth rate of the economy:

$$
\gamma=\frac{1}{\theta}\left[(1-\alpha) \alpha^{\frac{1+\alpha}{1-\alpha}} \frac{L}{\mu}-m-\rho\right] .
$$

As expected, the growth rate is decreasing in the imitation rate, as the limited duration of the monopoly effectively reduces the private value of an innovation. If we were concerned about long-run growth only, it would then be clear that patents should always be fully and eternally protected. However, for a given level of technology, $A_{t}$, output is higher the shorter is the patent duration (higher $m$ ), as can be seen by substituting equilibrium quantities (21) and the ratio of imitated goods (20) in the production function (3):

$$
Y_{t}=\alpha^{2 \alpha /(1-\alpha)} A_{t} L\left[1+\left(\frac{m}{\gamma+m}\right)\left(\alpha^{-\alpha /(1-\alpha)}-1\right)\right]
$$

Therefore, a reduction in the patent life entails a trade-off between an immediate consumption gain and future losses in terms of lower growth, and its quantitative analysis requires the calculation of welfare along the transition. Kwan and Lai (2003) perform such an analysis, both numerically and by linearizing the BG equilibrium in the neighborhood of the steady-state, and show the existence of an optimum patent life. They

\footnotetext{
${ }^{11} \mathrm{~A}$ simple way of seeing this is through the following argument. In a time interval $d t$, the firm provides a profit stream $\pi \cdot d t$, a capital gain of $V \cdot d t$ if not imitated and a capital loss $V$ if imitated (as the value of the patent would drop to zero). In the limit $d t \rightarrow 0$, the probability of being imitated in this time interval is $m \cdot d t$ and the probability of not being imitated equals $(1-m \cdot d t)$. Therefore, the expected return for the firm is $\pi \cdot d t+(1-m \cdot d t) \dot{V} \cdot d t-m V \cdot d t$. Selling the firm and investing the proceeds in the capital market would yield an interest payment of $r V \cdot d t$. Arbitrage implies that the returns from these two forms of investment should be equal and in a steady state $\dot{V}=0$, implying $\pi / V=r+m$.
} 
also provide a simple calibration, using US data on long-run growth, markups and plausible values for $\rho$ and $\theta$, to suggest that over-protection of patents is unlikely to happen, whereas the welfare cost of under-protection can be substantial.

Alternatively, the optimal patent length can be analytically derived in models with a simpler structure. For example, Grossman and Lai (2004) construct a modified version of the model described above, where they assume quasi-linear functions. They show the optimal patent length to be an increasing function of the useful life of a product, of consumers' patience and the ratio of consumers' and producers' surplus under monopoly to consumers' surplus under competition. In addition, they derive the optimal patent length for noncooperative trading countries and find that advanced economies with a higher innovative potential will, in general, grant longer patents. A similar point is made in Lai and Qin (2003).

\section{Trade, Growth and Imitation}

Growth models with an expanding variety of products are a natural dynamic counterpart to the widely-used trade models based on increasing returns and product differentiation developed in the 1980s (e.g., Helpman and Krugman, 1985). As such, they offer a simple framework for studying the effects of market integration on growth and other issues in dynamic trade theory. Quality-ladder models have also been proposed in this literature, but they are a less natural counterpart to the static new trade theory, as they do not focus on the number of varieties available in an economy and their growth rate. As we shall see, economic integration can provide both static gains, through the access to a wider range of goods, and dynamic gains, through an increase in the rate at which new varieties are introduced. However, the results may vary when integration is limited to commodity markets with no international diffusion of knowledge (Romer and RiveraBatiz, 1991a) and when countries differ in their initial stock of knowledge (Devereux and Lapham, 1994).

Finally, the analysis in this section is extended to product-cycle trade: the introduction of new products in advanced countries and their subsequent imitation by less developed countries. An important result will be to show that, contrary to the closed economy case, imitation by less developed countries may spur innovation and growth (Helpman, 1993).

\subsection{Scale Effects, Economic Integration and Trade}

In this section, we use the benchmark model to discuss the effects of trade and integration. The model features scale effects. Take two identical countries with identical labor endowment, $L=L^{*}$. In isolation, both countries would grow at the same rate, as given by (15). But if they merge, the growth rate of the integrated country increases to:

$$
\gamma^{I}=\frac{\delta \alpha\left(L+L^{*}\right)-\rho}{\alpha+\theta}=\frac{2 \alpha \delta L-\rho}{\alpha+\theta} .
$$

Therefore, the model predicts that economic integration boosts growth.

Integration, even if beneficial, may be difficult to achieve. However, in many instances, trade operates as a substitute for economic integration. Romer and Rivera- 
Batiz (1991a) analyze under which condition trade would attain the same benefits as economic integration. To this aim, they consider two experiments: ${ }^{12}$

1. The economies can trade at no cost in goods and assets, but knowledge spillovers remain localized within national borders;

2. In addition, knowledge spillovers work across borders after trade.

In both cases, to simplify the analysis, the two economies are assumed to produce, before trade, disjoint subsets of intermediate goods. This assumptions avoids complications arising from trade turning monopolies into duopolies in those industries which exist in both countries. Clearly, after trade, there would be no incentive for overlap in innovation, and the importance of inputs that were historically produced in both countries would decline to zero over time.

We start from the case analyzed by Romer and Rivera-Batiz (1991a), where the two countries are perfectly identical before trade. Namely, $L=L^{*}$ and $A_{0}=A_{0}^{*}$, where the star denotes the foreign economy, and time zero denotes the moment when trade starts. Since, in a BG equilibrium, $\gamma=\delta L_{x}$, trade can only affect growth via the split of the workforce between production and research. Such a split, however, is not affected by trade, for in the symmetric equilibrium, trade increases by the same proportion the productivity of workers in production and the profitability of research. Since both the cost and private benefit of innovation increase by the same factor, investments in innovation remain unchanged.

More formally, the after trade wage is:

$$
w_{\text {trade }}=(1-\alpha) L_{y}^{-\alpha} x^{\alpha}\left(A+A^{*}\right)
$$

which is twice as large as in the pre-trade equilibrium since at the moment of trade liberalization, $A=A^{*}$. Higher labor costs are a disincentive to research. But trade also increases the market for intermediate goods. Each monopolist can now sell its product in two markets. Since the demand elasticity is the same in both markets, the monopoly price equals $1 / \alpha$ in both markets. Thus, the after trade profit is

$$
\pi_{\text {trade }}=(p-1)\left(x+x^{*}\right)=2 \frac{1-\alpha}{\alpha} \alpha^{\frac{2}{1-\alpha}} L_{y} .
$$

The free-entry condition becomes, for both countries:

$$
2 \frac{\frac{1-\alpha}{\alpha} \alpha^{\frac{2}{1-\alpha}} L_{y}}{r} \leq 2 \frac{(1-\alpha) \alpha^{\frac{2 \alpha}{1-\alpha}}}{\delta}
$$

which, after simplifying, is identical to (12). Therefore, the split of the workforce between production and research remains unchanged, and trade has no permanent effects on growth. Opening up to free trade, however, induces a once-and-for-all gain: both output

\footnotetext{
${ }^{12}$ The original article considers two versions of the model, one using the benchmark set-up and the other using the "lab-equipment" version. For the sake of brevity, we restrict the attention to the first. Romer (1994) extends the analysis to the case when a tariff on imports is imposed.
} 
and consumption increase in both countries, similarly to an unexpected increase in the stock of knowledge, since final producers in both countries can use a larger set of intermediate goods.

This result is not robust to asymmetric initial conditions. Devereux and Lapham (1994) show that if, initially, the two countries have different productivity levels, trade leads to specialization and a rise in the world growth rate. ${ }^{13}$ Consider the economies described above, but assume that $A_{0}<A_{0}^{*}$. Recall that free-entry implies:

$$
V \leq \frac{w}{\delta A}, \text { and } V^{*} \leq \frac{w^{*}}{\delta A^{*}},
$$

where $V, V^{*}$ denote the PDV of profits for an intermediate firm located at home and abroad, respectively. First, trade in intermediate goods and free capital markets equalize the rate of return to both financial assets $(r)$ and labor $(w) .{ }^{14}$ Second, monopoly profits are independent of firms' locations, thereby implying that the value of firms must be the same all over the world: $V=V^{*}=V^{w}$. Therefore, at the time of trade liberalization, we must have:

$$
\frac{w_{\text {trade }}}{\delta A}>\frac{w_{\text {trade }}}{\delta A^{*}} \geq V^{w}
$$

implying that no innovation is carried out in equilibrium in the (home) country, starting from a lower productivity. Moreover, the productivity gap in $\mathrm{R} \& \mathrm{D}$ widens over time: indeed, trade forever eliminates the incentives to innovate in the initially poorer country.

In the richer (foreign) country, however, trade boosts innovation. ${ }^{15}$ The value of foreign firms must satisfy the following Bellman equation:

$$
r V^{*}=\dot{V}^{*}+\frac{1-\alpha}{\alpha} \alpha^{\frac{2}{1-\alpha}}\left(L_{y}^{*}+L\right),
$$

where we note that $L_{y}=L$. The free-entry condition implies that:

$$
V^{*}=\frac{(1-\alpha) \alpha^{\frac{2 \alpha}{1-\alpha}}}{\delta} \frac{A^{*}+A}{A^{*}} .
$$

Since knowledge only accumulates in the foreign country, the value of intermediate firms must decline over time, and in the long-run tend to its pre-trade value, i.e., $V^{*}=$ $(1-\alpha) \alpha^{\frac{2 \alpha}{1-\alpha}} / \delta$. Therefore, in the long run, the free-entry condition is:

$$
\frac{\frac{1-\alpha}{\alpha} \alpha^{\frac{2}{1-\alpha}}\left(L+L_{y}^{*}\right)}{r} \leq \frac{(1-\alpha) \alpha^{\frac{2 \alpha}{1-\alpha}}}{\delta}
$$

\footnotetext{
${ }^{13}$ See also Romer and Rivera-Batiz (1991b) on the effects of trade restrictions with asymmetric countries.

${ }^{14}$ Recall equation (22). The equalization of wages descends from a particular feature of the equilibrium, i.e., that the marginal product of labor is independent of the level of employment in production (since $x$ is linear in $L_{y}$ ). This feature is not robust. If the production technology had land as an input, for instance, wages would not be equalized across countries; see Devereux and Lapham (1994) for an analysis of the more general case.

${ }^{15}$ Our discussion focuses on a world where no economy becomes fully specialized in research, since this seems to be the empirically plausible case.
} 
Comparing (24) with (12) shows that trade reduces employment in production and, consequently, increases the long-run research activity in the foreign country, which implies that trade increases growth. In terms of figure 1, trade creates an outward shift in the DD schedule, leading to a higher interest rate and faster growth in equilibrium.

The result can be interpreted as trade leading to specialization. The home country specializes in final production, while the foreign country diversifies between manufacturing and innovation. ${ }^{16}$ This is efficient, since there are country-wide economies of scale in innovation. Although trade leads to zero innovation in the home country, markets are integrated: final good producers, in both countries, can use the same varieties of intermediates and all consumers in the world can invest in the innovative firms of the foreign economy. Therefore, the location of innovation and firms has no impact on the relative welfare of the two countries.

Consider now the case when trade induces cross-country flows of ideas, i.e., if the knowledge spillover is determined, after trade, by the world stock of ideas contained in the union of $A$ and $A^{*}$. When free trade is allowed, the accumulation of knowledge in each country is given by:

$$
\dot{A}=\delta L_{x}\left(A+A^{*}\right) \text { and } \dot{A}^{*}=\delta L_{x}^{*}\left(A+A^{*}\right) .
$$

Even if trade did not affect the allocation of the workforce between production and research, the rate of growth of technology would increase. But there is an additional effect; the larger knowledge spillover increases labor productivity in research, inducing an increase of employment in research. Formally, the total effect is equivalent to an increase in parameter $\delta$. In terms of figure 1, trade in goods plus flow of ideas imply an upward shift of the $D D$ locus for both countries. Hence, trade attains the same effect as economic integration (increasing $\delta$ is equivalent to increasing $L$ ). This result is robust to asymmetric initial conditions.

\subsection{Innovation, Imitation and Product Cycles}

The model just presented may be appropriate for describing trade integration between similar countries, but it misses important features of North-South trade. In a seminal article, Vernon (1966) argued that new products are first introduced in rich countries (the North), where R\&D capabilities are high and the proximity to large and rich markets facilitates innovation. After some time, when a product reaches a stage of maturity and manufacturing methods become standardized, the good can easily be imitated and then, the bulk of production moves to less developed countries (the South), to take advantage of low wages. The expanding variety model provides a natural framework for studying the introduction of new goods and their subsequent imitation (product cycle trade). ${ }^{17}$ We have already discussed imitation within the context of a closed economy. Here, we extend the analysis to the case where a richer North innovates, while a poorer South only

\footnotetext{
${ }^{16}$ Home-country patent holders will still produce intermediates, but as compared to the world's stock of intermediates, they will be of measure zero.

${ }^{17}$ Quality ladder models of innovation have been used to study product-cycles by, among others, Grossman and Helpman (1991), Segerstom et al. (1991) and Dinopoulos and Segerstrom (2003).
} 
engages in imitation. The analysis yields new results that modify some of the previous conclusions on the effect of imitation on innovation. The key questions are, first, how the transfer of production to the South through imitation affects the incentives to innovate and, second, how it affects the income distribution between North and South.

Following Helpman (1993), consider a two-region model of innovation, imitation and trade. Assume that $\mathrm{R} \& \mathrm{D}$, producing new goods, is performed in the North only and that costless imitation takes place in the South at a constant rate $m .{ }^{18}$ The imitation rate can be interpreted as an inverse measure of protection of Intellectual Property Rights (IPRs). Once a good is copied in the South, it is produced by competitive firms. Therefore, at every point in time, there is a range $A_{t}^{N}$ of goods produced by monopolists in the North and a range $A_{t}^{S}$ of goods that have been copied and are produced in the South by competitive firms. Given that the rate of introduction of new good is $\gamma=\dot{A}_{t} / A_{t}$, where $A_{t}=A_{t}^{N}+A_{t}^{S}$, and that monopolized goods are copied at the instantaneous rate $m, A_{t}^{S}=m A_{t}^{N}$, it follows that a steady-state where the ratio $A_{t}^{N} / A_{t}^{S}$ is constant must satisfy:

$$
\frac{A^{N}}{A}=\frac{\gamma}{\gamma+m} \quad \text { and } \quad \frac{A^{S}}{A}=\frac{m}{\gamma+m} .
$$

We use the "labor-for-intermediates" version of the growth model, so that the price of a single variety depends on the prevailing wage rate in the country where it is manufactured. This is an important feature of product cycle models, allowing the North to benefit from low production costs in the South for imitated goods. Therefore, we define the aggregate production function as in (18):

$$
Y_{t}=\int_{0}^{A_{t}} x_{i}^{\alpha} d i
$$

where $A_{t}$ is the (growing) range of available products $x_{i}$ and $\epsilon=1 /(1-\alpha)$ is the elasticity of substitution between any two varieties. Intermediates are manufactured with $1 / A_{t}$ units of labor per unit of output in both regions. Northern firms charge a monopoly price, as long as their products have not been imitated, equal to a constant markup $1 / \alpha$ over the production cost, given by the wage rate. On the contrary, Southern firms produce imitated goods that have become competitive and sell them at a price equal to the marginal cost. To summarize:

$$
p_{t}^{N}=\frac{w_{t}^{N}}{\alpha A_{t}} \quad \text { and } \quad p_{t}^{S}=\frac{w_{t}^{S}}{A_{t}}
$$

where $p_{t}^{N}$ and $p_{t}^{S}$ are the prices of any variety of intermediates produced in the North and South, respectively.

As in the benchmark model, innovation requires labor: the introduction of new products per unit of time $A_{t}$ equals $\delta A_{t} L_{x}$, where $L_{x}$ is the (Northern) labor input employed in $\mathrm{R} \& \mathrm{D}, \delta$ is a productivity parameter and $A_{t}$ captures an externality from

\footnotetext{
${ }^{18}$ The rate of imitation is made endogenous in Grossman and Helpman (1991b).
} 
past innovations. This implies that the growth rate of the economy is a linear function of the number of workers employed in $\mathrm{R} \& \mathrm{D}, \gamma=L_{x} \delta$. As usual, profits generated by the monopoly over the sale of the new good are used to cover the cost of innovation. Since the profits per product are a fraction $(1-\alpha)$ of total revenue $p^{N} x$ and the labor market clears, $A_{t}^{N} x / A_{t}+\gamma / \delta=L^{N}$, profits can be written as:

$$
\pi^{N}=\frac{1-\alpha}{\alpha} \frac{w_{t}^{N}}{A_{t}^{N}}\left(L^{N}-\frac{\gamma}{\delta}\right)
$$

Arbitrage in asset markets implies that $(r+m) V^{N}=\pi^{N}+V^{N}$, where $V^{N}$ is the PDV of a new good and the effective interest rate is adjusted by the imitation risk. Along a BG path, $V^{N}=0$ and free entry ensures that the value of an innovation equals its cost, $w_{t}^{N} / \delta A_{t}$. Combining these considerations with (25) and (28) yields:

$$
\frac{1-\alpha}{\alpha}\left(\delta L^{N}-\gamma\right) \frac{\gamma+m}{\gamma}=r+m
$$

Together with the Euler equation for consumption growth, (29) provides an implicit solution for the long-run growth rate of innovation. Note that the left-hand side is the profit rate (i.e., instantaneous profits over the value of the innovation) and the right-hand side represents the effective cost of capital, inclusive of the imitation risk.

To see the effect of a tightening of IPRs (a reduction of $m$ ), consider how an infinitesimal change in $m$ affects the two sides of (29). Taking a log linear approximation, the impact of $m$ on the profit rate is $1 /(\gamma+m)$, whereas the effect on the cost of capital is $1 /(r+m)$. In the case of log preferences, studied by Helpman (1993), $r>\gamma$. Hence, a reduction of $m$ has a larger impact on the profit rate than on the effective cost of capital, thereby reducing the profitability of innovation and growth. What is the effect on the fraction of goods produced in the North? Rewriting (29) with the help of (25) as:

$$
\frac{A^{N}}{A}=\frac{1-\alpha}{\alpha}\left(\delta L^{N}-\gamma\right) \frac{1}{r+m},
$$

it becomes apparent that a reduction of $m$ increases the share of goods manufactured in the North, both through its direct effect and by reducing $\gamma$ and $r$.

To understand these results, note that stronger IPRs have two opposite effects. First, a lower imitation rate prolongs the expected duration of the monopoly on a new product developed in the North, thereby increasing the returns to innovation. Second, since firms produce for a longer time in the North, it rises the demand for Northern labor, $w^{N}$, and hence, the cost of innovation. For the specification with log utility, the latter effect dominates and innovation declines. More generally, the link between the rate of imitation and innovation can go either way (as in Grossman and Helpman, 1991a). However, the important result here is that tighter IPRs does not necessarily stimulate innovation in the long run.

The effect of IPRs on the North-South wage ratio can be found using (27), together 
with the relative demand for intermediates: ${ }^{19}$

$$
\frac{w^{N}}{w^{S}}=\alpha\left[\frac{A^{N}}{A^{S}} \frac{L_{S}}{L_{N}-\gamma / \delta}\right]^{1 / \epsilon} .
$$

Given that a decline in the imitation rate $m$ raises $\left(A^{N} / A^{S}\right) /\left(L_{N}-\gamma / \delta\right)$ (see equation (30)), a tightening of IPRs raises the relative wage of the North. Helpman (1993) computes welfare changes in the North and in the South (including transitional dynamics) after a change in the imitation rate $m$, and concludes that the South is unambiguously hurt by a decline in imitation. Moreover, if the imitation rate is not too high, the North can also be worse-off.

More recent papers on product cycles, incorporating the notion that stronger IPRs make relocation of production to the South a more attractive option, have come to different conclusions. For example, by assuming that Northern multinationals can produce in the South and that Southern firms can only imitate after production has been transferred to their country, Lai (1998) shows that stronger IPRs increase the rate of product innovation and the relative wage of the South. Similarly, Yang and Maskus (2001) find that if Northern firms can licence their technology to Southern producers, being subject to an imitation risk, stronger IPRs reduce the cost of licensing, free resources for $R \& D$ and foster growth, with ambiguous effects on relative wages. Finally, the literature on appropriate technology (e.g., Diwan and Rodrik, 1991, Acemoglu and Zilibotti, 2001, Gancia, 2003) has shown that, when the North and the South have different technological needs, the South has an incentive to protect IPRs in order to attract innovations more suited to their technological needs. Some of these results are discussed in the next sections.

\section{Directed Technichl Change}

So far, technical progress has been modeled as an increase in total factor productivity $(A)$ that is neutral towards different factors and sectors. For many applications, however, this assumption is not realistic. For example, there is evidence that technical progress has been skill-biased during the last century and that this bias accelerated during the 1980s. Similarly, the fact that the output shares of labor and capital have been roughly constant in the US while the capital-labor ratio has been steadily increasing suggests that technical change has mainly been labor-augmenting. ${ }^{20}$ Further, industry studies show R\&D intensity to vary substantially across sectors. In order to build a theory for the direction of technical change, a first step is to introduce more sectors into the

${ }^{19}$ Relative demand for intermediates is:

$$
\frac{p^{N}}{p^{S}}=\left(\frac{x^{N}}{x^{S}}\right)^{\alpha-1} .
$$

Using $x^{N}=A L_{y}^{N} / A^{N}, x^{S}=A L_{y}^{S} / A^{S}$ and the pricing formula (27) yields the expression in the text.

${ }^{20}$ Unless the production function is Cobb-Douglas, in which case the direction of technical progress is irrelevant. Empirical estimates suggest that the elasticity of substitution between labor and capital is likely to be less than one. See Hamermesh (1993) for a survey of early estimates and Krusell et al. (2000) and Antras (2003) for more recent contributions. 
model. Then, studying the economic incentives to develop technologies complementing a specific factor or sector can help understand what determines the shape of technology.

An important contribution of this new theory will be to shed light on the determinants of wage inequality (Acemoglu, 1998, 2003a). Another application studies under which circumstances technologies developed by profit-motivated firms are appropriate for the economic conditions of the countries where they are used. The analysis will demonstrate that, since IPRs are weakly protected in developing countries, new technologies tend to be designed for the markets and needs of advanced countries. As a result, these technologies yield a low level of productivity when adopted by developing countries (Acemoglu and Zilibotti, 2001). Trade can reinforce this problem and create interesting general equilibrium effects.

Although most of the results discussed in this section can be derived using models of vertical innovation, the expanding variety approach has proven to be particularly suited for addressing these issues because of its analytical tractability and simple dynamics. For instance, creative destruction, a fundamental feature of quality-ladder models, is not a crucial element for the problems at hand, and abstracting from it substantially simplifies the analysis.

\subsection{Factor-Biased Innovation and Wage Inequality}

Directed technical change was formalized by Acemoglu (1998), and then integrated by Acemoglu and Zilibotti (2001) into a model of growth with expanding variety, to explain the degree of skill-complementarity of technology. ${ }^{21}$ In this section, we discuss the expanding variety version (following the synthesis of Acemoglu, 2002) by extending the "lab-equipment" model to two sectors employing skilled and unskilled labor, respectively. Consider the following aggregate production function:

$$
Y=\left[Y_{L}^{(\epsilon-1) / \epsilon}+Y_{H}^{(\epsilon-1) / \epsilon}\right]^{\epsilon /(\epsilon-1)},
$$

where $Y_{L}$ and $Y_{H}$ are goods produced with unskilled labor, $L$, and skilled labor, $H$, respectively. $Y$ represents aggregate output, used for both consumption and investment, as a combination of the two goods produced in the economy, with an elasticity of substitution equal to $\epsilon$. Maximizing $Y$ under a resource constraint gives constant elasticity demand functions, implying a negative relationship between relative prices and relative quantities:

$$
\frac{P_{H}}{P_{L}}=\left[\frac{Y_{L}}{Y_{H}}\right]^{1 / \epsilon},
$$

where $P_{L}$ and $P_{H}$ are the prices of $Y_{L}$ and $Y_{H}$, respectively. Aggregate output is chosen as the numeraire, hence:

$$
\left(P_{L}^{1-\epsilon}+P_{H}^{1-\epsilon}\right)^{1 /(1-\epsilon)}=1 .
$$

The distinctive feature of this model is that the two goods are now produced using

\footnotetext{
${ }^{21}$ Important antecedents are Kennedy (1964), Samuelson (1965) and Atkinson and Stiglitz (1969).
} 
different technologies:

$$
\begin{aligned}
Y_{L} & =L^{1-\alpha} \int_{0}^{A_{L}} x_{L, j}{ }^{\alpha} d j \\
Y_{H} & =H^{1-\alpha} \int_{0}^{A_{H}} x_{H, j}{ }^{\alpha} d j,
\end{aligned}
$$

where $x_{L, j}, j \in\left[0, A_{L}\right]$, are intermediate goods complementing unskilled labor, whereas $x_{H, j}, j \in\left[0, A_{H}\right]$ complement skilled labor. This assumption captures the fact that different factors usually operate with different technologies and that a new technology may benefit one factor more than others. ${ }^{22}$ For example, it has been argued that computers boosted the productivity of skilled more than that of unskilled labor, whereas the opposite occurred after the introduction of the assembly line. As before, technical progress takes the form of an increase in the number of intermediate goods, $\left[A_{L}, A_{H}\right]$, but now an innovator must decide which technology to expand. The profitability of the two sectors pins down, endogenously, the direction of technical change. In a steady-state equilibrium, there is a constant ratio of the number of intermediates used by each factor, $A_{H} / A_{L}$, and this can be interpreted as the extent of the "endogenous skill-bias" of the technology.

The analysis follows the same steps as in model with a single factor. Final good producers take the price of their output $\left(P_{L}, P_{H},\right)$, the price of intermediates $\left(p_{L, j}, p_{H, j}\right)$ and wages $\left(w_{L}, w_{H}\right)$ as given. Consider a variety $j$ used in the production of $Y_{L}$. Profit maximization gives the following isoelastic demand:

$$
x_{L, j}=\left[\frac{\alpha P_{L}}{p_{L, j}}\right]^{\frac{1}{1-\alpha}} L,
$$

and an equivalent expression for $x_{H, j}$.

The intermediate good sector is monopolistic, with each producer owning the patent for a single variety. The cost of producing one unit of any intermediate good is one unit of the numeraire. The symmetric structure of demand and technology implies that all monopolists set the same price, $p_{L j}=p_{L}$. In particular, given the isoelastic demand, they set $p_{L}=1 / \alpha$ and sell the quantity $x_{L, j}=\left(\alpha^{2} P_{L}\right)^{\frac{1}{1-\alpha}} L$. The profit flow accruing to intermediate producers can therefore be expressed as

$$
\pi_{L}=(1-\alpha) \alpha^{\frac{1+\alpha}{1-\alpha}}\left(P_{L}\right)^{\frac{1}{1-\alpha}} L .
$$

Similar conclusions are reached for varieties used in the production of $Y_{H}$, leading to

$$
\pi_{H}=(1-\alpha) \alpha^{\frac{1+\alpha}{1-\alpha}}\left(P_{H}\right)^{\frac{1}{1-\alpha}} H .
$$

$>$ From (37)-(38), it immediately follows that the relative profitability in the two sectors is given by

$$
\frac{\pi_{H}}{\pi_{L}}=\left(\frac{P_{H}}{P_{L}}\right)^{1 /(1-\alpha)} \frac{H}{L},
$$

\footnotetext{
${ }^{22}$ The analysis can be generalized to specifications where, in the spirit of Heckscher-Ohlin models, each sector uses all productive factors, but factor intensities differ across sectors. The model can also be generalized to more than two factors and sectors.
} 
which, since profits are used to finance innovation, is also the relative profitability of R\&D directed to the two sectors. The first term in (39) represents the "price effect": there is a greater incentive to invent technologies producing more expensive goods. ${ }^{23}$ The second term is the "market size" effect: the incentive to develop a new technology is proportional to the number of workers that will be using it. ${ }^{24}$

Next, using the price of intermediates in (36) and (35) gives final output in each sector:

$$
\begin{aligned}
Y_{L} & =\alpha^{\frac{2 \alpha}{1-\alpha}} P_{L}^{\alpha /(1-\alpha)} A_{L} L \\
Y_{H} & =\alpha^{\frac{2 \alpha}{1-\alpha}} P_{H}^{\alpha /(1-\alpha)} A_{H} H .
\end{aligned}
$$

Note the similarity with (16). As in the benchmark model, output - in each sector - is a linear function of technology and labor. But sectoral output now also depends on sectoral prices, $P_{L}$ and $P_{H}$, since a higher price of output increases the value of productivity of intermediates, but not their costs, and therefore encourages firms to use more of them, thereby raising labor productivity. Note that this is not the case in the one-sector model since there, the price of output is proportional to the price of intermediates.

We can now solve for prices and wages as functions of the state of technology and endowments. Using (40) into (33) and noting that the wage bill is a constant fraction of sectoral output, yields:

$$
\begin{gathered}
\frac{P_{H}}{P_{L}}=\left[\frac{A_{H}}{A_{L}} \frac{H}{L}\right]^{-(1-\alpha) / \sigma} \\
\frac{w_{H}}{w_{L}}=\left[\frac{A_{H}}{A_{L}}\right]^{1-1 / \sigma}\left[\frac{H}{L}\right]^{-1 / \sigma},
\end{gathered}
$$

where $\sigma \equiv 1+(1-\alpha)(\epsilon-1)$ is, by definition, the elasticity of substitution between $H$ and $L .{ }^{25}$ Note that the skill premium, $w_{H} / w_{L}$, is decreasing in the relative supply of skilled labor $(H / L)$ and increasing in the skill-bias $\left(A_{H} / A_{L}\right)$.

The final step is to find the equilibrium for technology. We assume, as in the labequipment model of section 2.2, that the development of a new intermediate good to require a fixed cost of $\mu$ units of the numeraire. Free entry and an arbitrage condition require the value $V_{z}$ of an innovation directed to factor $Z \in\{L, H\}$ to equal its cost. Since the value of an innovation is the PDV of the infinite stream of profits it generates, an equilibrium with a positive rate of innovation in both types of intermediates such that the ratio $A_{H} / A_{L}$ remains constant, i.e. a BG path where $P_{H} / P_{L}, w_{H} / w_{L}$ and $\pi_{H} / \pi_{L}$ are also constant, requires profit equalization in the two sectors, $\pi_{H}=\pi_{L}=\pi$. Imposing

\footnotetext{
${ }^{23}$ The price effect, restated in terms of factor prices, was emphasized by Hicks (1932) and Habakkuk (1962).

${ }^{24}$ Market size, although in the context of industry- and firm-level innovation, was emphasized as a determinant of technical progress by Griliches and Schmookler (1963), Schmookler (1966) and Schumpeter (1950).

${ }^{25}$ This is the short-run elasticity of substitution between $L$ and $H$, for a given technology $A_{L}$ and $A_{H}$.
} 
this restriction yields the equilibrium skill-bias of technology,

$$
\frac{A_{H}}{A_{L}}=\left[\frac{H}{L}\right]^{\sigma-1} .
$$

Equation (43) shows that, as long as workers of different skill levels are gross substitutes $(\sigma>1)$, an increase in the supply of one factor will induce more innovation directed to that specific factor. This is the case because, with $\sigma>1$, the market size effect dominates the price effect, and technology is biased towards the abundant factor. The opposite is true if $\sigma<1$. As usual, the growth rate of the economy can be found from the free-entry condition $\pi_{Z} / r=\mu, Z \in\{L, H\}$. Using (34), (41) and (43) to substitute for prices and the interest rate from the Euler equation, yields:

$$
\gamma=\frac{1}{\theta}\left[\frac{(1-\alpha) \alpha^{\frac{1+\alpha}{1-\alpha}}}{\mu}\left(L^{\sigma-1}+H^{\sigma-1}\right)^{1 /(\sigma-1)}-\rho\right] .
$$

If we only had one factor (e.g., $H=0$ ), the growth rate would reduce to that of the benchmark model.

Directed technical change has interesting implications on factor prices. Using (43), the skill-premium becomes:

$$
\frac{w_{H}}{w_{L}}=\left[\frac{H}{L}\right]^{\sigma-2} .
$$

Equation (44) shows that the slope of the labor demand curve, i.e., the relationship between relative wages and relative labor supply, can be either positive or negative and is the result of two opposite forces. On the one hand, a large supply of one factor depresses the price of its product while, on the other hand, it induces a technology bias in its favor, thereby raising its productivity. A high substitutability between $H$ and $L$ implies a weak price effect of an increase in relative supply, which makes a positive relationship more likely. In particular, if $\sigma>2$, the market size effect is sufficiently strong to not only dominate the price effect on technical change (see equation 43), but also the substitution effect between skilled and unskilled workers at a given technology.

This result can help rationalize several facts. First, it suggests that technical change has been skill biased during the past 60 years, because of the steady growth in the supply of skilled labor. Second, the case $\sigma>2$ offers an explanation for the fall and rise in the US skill premium during the 1970s and 1980s. In the 1970s, there was a large increase in the supply of skilled labor $(H / L)$. Assuming this shock to be unexpected, the model predicts an initial fall in the skill premium (recall that $A_{H} / A_{L}$ is a state variable that does not immediately adjust), followed by its rise due to the induced skill biased technical change, a pattern broadly consistent with the evidence.

In Acemoglu (2003b), this set-up is used to study the direction of technical progress when the two factors of production are capital and labor. Beyond the change of notation, the resulting model has an important qualitative difference, as capital can be accumulated. The main finding is that, when both capital and labor augmenting innovations are allowed, a balanced growth path still exists and features labor-augmenting 
technical progress only. The intuition is that, while there are two ways of increasing the production of capital-intensive goods (capital-augmenting technical change and accumulation), there is only one way of increasing the production of labor-intensive goods (labor-augmenting technical progress). Therefore, in the presence of capital accumulation, technical progress must be more labor-augmenting than capital-augmenting. Further, Acemoglu shows that, if capital and labor are gross complements (i.e., the elasticity of substitution between the two is less than one), which seems to be the empirically relevant case (see, for example, Antras, 2004), the economy converges to the balanced growth path.

Finally, the theory of directed technical change can be used to study which industries attract more innovation and why R\&D intensity differs across sectors. In this exercise, following a modified version of Klenow (1996), we abstract from factor endowments as determinants of technology, by assuming there to be a single primary input, which we call labor. Instead, other characteristics can make one sector more profitable than others. Major explanations put forward in the literature on innovation are industry differences in technological opportunities, market size and appropriability of rents, all factors that can easily be embedded in the basic model with two sectors. In particular, to capture the market size hypothesis, we introduce a parameter $\eta$ defining the relative importance of industry $i$ in aggregate consumption:

$$
Y=\left[\eta Y_{i}^{(\epsilon-1) / \epsilon}+(1-\eta) Y_{j}^{(\epsilon-1) / \epsilon}\right]^{\epsilon /(\epsilon-1)} .
$$

Differences in technological opportunities can be incorporated by allowing the cost of an innovation, $\mu_{i}$, to vary across sectors. Finally, we assume that an inventor in industry $i$ can only extract a fraction $\lambda_{i}$ of the profits generated by his innovation. The previous analysis carries over almost unchanged, with the main difference that we now need to solve for the allocation of labor across industries. This can be done requiring all industries to pay the same wage, i.e., setting (42) equal to one:

$$
\frac{L_{i}}{L_{j}}=\left(\frac{A_{i}}{A_{j}}\right)^{\sigma-1} \text {. }
$$

Solving the new arbitrage condition stating that innovation for the two industries should be equally profitable in $\mathrm{BG}, \lambda_{i} \pi_{i} / \mu_{i}=\lambda_{j} \pi_{j} / \mu_{j}$, yields the relative industry-bias of technology:

$$
\frac{A_{i}}{A_{j}}=\left(\frac{\lambda_{i}}{\lambda_{j}} \frac{\mu_{j}}{\mu_{i}}\right)^{1 /(2-\sigma)}\left(\frac{\eta}{1-\eta}\right)^{\epsilon /(2-\sigma)} .
$$

As expected, industries with a larger market size, better technological opportunities and higher appropriability attract more innovations. ${ }^{26}$ Empirical estimates surveyed by Cohen and Levin (1989) suggest that about one half of the industry differences in research intensity can be attributed to the available measures of these three factors.

\footnotetext{
${ }^{26}$ This is true as long as $\sigma<2$. This restriction is required to have balanced growth. If violated, e.g. if goods are highly substitutable, it would be profitable to direct innovation to one sector only.
} 


\subsection{Appropriate Technology and Development}

Directed technical change has interesting implications for the analysis of some development issues. Acemoglu and Zilibotti (2001) show that technologies resulting from directed technical change are optimal for the economic conditions of the markets where they are sold. They analyze the implications of this finding in a two-country world where technological innovation takes place in the North, and the South does not enforce (or imperfectly enforce) IPRs. In this environment, innovators in the North can only extract rents from selling technologies (embodied in new varieties of intermediate goods) in the Northern market, since new technologies can be copied and locally produced in the South. Thus, innovation does not respond to the factor endowment of the South: the equilibrium skill-bias of technical change (see equation (43) in the previous section) is determined by the factor endowment of the North only. In this sense, technological development tends to be "inappropriate" for the South: there is too much investment in inventing new technologies augmenting the productivity of skilled workers, and too little in inventing new technologies augmenting the productivity of unskilled workers. Such excessive skill-bias prevents the South from fully profiting from technological improvements. The theory can explain North-South productivity differences, even when the technology is identical and there are no significant barriers to technology adoption. ${ }^{27}$

We start by studying the set of advanced countries, called North. A continuum of measure one of final goods is produced by competitive firms. Final goods, indexed by $i \in[0,1]$, are aggregated to give a composite output, $Y=\exp \left(\int_{0}^{1} \log y_{i} d i\right)$, which is the numeraire. There are two differences with respect to the model of the previous section: first, there is a continuum of sectors, not just two, and second, the elasticity of substitution between sectors is unity. ${ }^{28}$ Each good $i$ can be produced with both skilled and unskilled labor using two sets of intermediate goods: intermediates $\left[0, A_{L}\right]$ used by unskilled workers only and intermediates $\left[0, A_{H}\right]$ used by skilled workers only. Therefore, despite the continuum of sectors, there are only two types of technologies, as in the basic model of directed technical change. The production function takes the following form:

$$
y_{i}=\left[(1-i) l_{i}\right]^{1-\alpha} \int_{0}^{A_{L}} x_{L, v, i}^{\alpha} d v+\left[i h_{i}\right]^{1-\alpha} \int_{0}^{A_{H}} x_{H, v, i}^{\alpha} d v,
$$

where $l_{i}$ and $h_{i}$ are the quantities of unskilled and skilled labor employed in sector $i$, respectively, and $x_{z, v, i}$ is the quantity of intermediate good of type $v$ used in sector $i$ together with the labor of skill level $z=L, H$. Note that sectors differ in laboraugmenting productivity parameters, $(1-i)$ for the unskilled technology and $i$ for the skilled technology, so that unskilled labor has a comparative advantage in sectors with a low index. Producers of good $i$ take the price of their product, $P_{i}$, the price of

\footnotetext{
${ }^{27}$ Evidence on cross-country TFP differences is provided by, among others, Klenow and Rodriguez (1997), Hall and Jones (1998), Caselli, Esquivel and Lefort (1997) and Prescott (1998). The view that technological differences arise from barriers to technology adoption is expressed by, among others, Parente and Prescott (1994) and Prescott (1998).

${ }^{28}$ The composite output $Y$ can be interpreted as a symmetric Cobb Douglas over the measure of final goods $i \in[0,1]$.
} 
intermediates $\left(p_{L, v}, p_{H, v}\right)$ and wages $\left(w_{L}, w_{H}\right)$ as given. Profit maximization gives the following demands for intermediates:

$$
x_{L, v, i}=(1-i) l_{i}\left[\alpha P_{i} / p_{L, v}\right]^{1 /(1-\alpha)} \text { and } x_{H, v, i}=i h_{i}\left[\alpha P_{i} / p_{H, v}\right]^{1 /(1-\alpha)} .
$$

The intermediate good sector is monopolistic. Each producer holds the patent for a single type of intermediate good $v$, and sells its output to firms in the final good sectors. The cost of producing one unit of any intermediate is conveniently normalized to $\alpha^{2}$ units of the numeraire. Profit maximization by monopolists implies that prices are a constant markup over marginal costs, $p=\alpha$. Using the price of intermediates together with (46) and (45) gives the final output of sector $i$ as a linear function of the number of intermediate goods and labor:

$$
y_{i}=P_{i}^{\alpha /(1-\alpha)}\left[A_{L}(1-i) l_{i}+A_{H} i h_{i}\right] .
$$

$>$ From (47), it is easily seen that all sectors whose index $i$ is below a threshold level $J$ will use the unskilled technology only and the remaining sectors will employ the skilled technology only. This happens because of the comparative advantage of unskilled workers in low index sectors and the linearity of the production function (there is no incentive to combine the two technologies and, for a given $i$, one always dominates the other). The total profits earned by monopolists are:

$$
\pi_{L, v}=(1-\alpha) \alpha \int_{0}^{1} P_{i}^{1 /(1-\alpha)}(1-i) l_{i} d i \quad \text { and } \quad \pi_{H, v}=(1-\alpha) \alpha \int_{0}^{1} P_{i}^{1 /(1-\alpha)} i h_{i} d i .
$$

Note that, by symmetry, $\pi_{L, v}=\pi_{L, j}$ and $\pi_{H, v}=\pi_{H, j}$. Given the Cobb-Douglas specification in (45), the wage bill in each sector is a fraction $(1-\alpha)$ of sectoral output. Therefore, equation (47) can be used to find wages: ${ }^{29}$

$$
w_{L}=(1-\alpha) P_{i}^{1 /(1-\alpha)} A_{L}(1-i) \text { and } w_{H}=(1-\alpha) P_{i}^{1 /(1-\alpha)} A_{H} i .
$$

Defining $P_{L} \equiv P_{0}, P_{H} \equiv P_{1}$ and dividing equations in (49) by their counterparts in sectors 0 and 1 , respectively, it is possible to derive the following pattern of prices: for $i \leq J, P_{i}=P_{L}(1-i)^{-(1-\alpha)}$ and for $i \geq J, P_{i}=P_{H} i^{-(1-\alpha)}$. Intuitively, the price of a good produced with skilled (unskilled) labor is decreasing in the sectoral productivity of skilled (unskilled) workers. Next, note that to maximize $Y$, expenditures across goods must be equalized, i.e., $P_{i} y_{i}=P_{H} y_{1}=P_{L} y_{0}$ (as for a symmetric Cobb-Douglas). This observation, plus the given pattern of prices and full employment, imply that labor is evenly distributed among sectors: $l_{i}=L / J, h_{i}=H /(1-J)$, as prices and sectoral productivity compensate each other. Finally, in sector $i=J$, it must be the case that both technologies are equally profitable or $P_{L}(1-J)^{-(1-\alpha)}=P_{H} J^{-(1-\alpha)}$; this condition, using $P_{H} y_{1}=P_{L} y_{0}$ and (47), yields:

$$
\frac{J}{1-J}=\left(\frac{P_{H}}{P_{L}}\right)^{1 /(1-\alpha)}=\left(\frac{A_{H}}{A_{L}} \frac{H}{L}\right)^{-1 / 2} .
$$

\footnotetext{
${ }^{29}$ In Acemoglu and Zilibotti (2001), there is an additional parameter $(Z>1)$, which is here omitted for simplicity, which augments the productivity of skilled workers, ensuring that the skill premium is positive in equilibrium.
} 
The higher the relative endowment of skill $(H / L)$ and the skill-bias of technology $\left(A_{H} / A_{L}\right)$, the larger the fraction of sectors using the skill-intensive technology $(1-J)$. Finally, integrating $P_{i} y_{i}$ over $[0,1]$, using $(47),(50)$ and the fact that the consumption aggregate is the numeraire (i.e., $\exp \left[\int_{0}^{1} \ln P_{i} d i\right]=1$ ) gives a simple representation for aggregate output:

$$
Y=\exp (-1)\left[\left(A_{L} L\right)^{1 / 2}+\left(A_{H} H\right)^{1 / 2}\right]^{2},
$$

which is a CES function of technology and endowments, with an elasticity of substitution between factors equal to two.

So far, the analysis defines an equilibrium for a given technology. Next, we need to study innovation and characterize the equilibrium skill-bias of technology, $\left(A_{H} / A_{L}\right)$. As before, technical progress takes the form of an increase in $A_{L}$ and $A_{H}$ and is the result of directed $\mathrm{R} \& \mathrm{D}$ investment. The cost of an innovation (of any type) is equal to $\mu$ units of the numeraire, and R\&D is profitable as long as the PDV of the infinite flow of profits that a producer of a new intermediate expects to earn covers the fixed cost of innovation. Finally, free entry ensures that there are no additional profits. Using the price pattern, instantaneous profits can be simplified as:

$$
\pi_{H}=\alpha(1-\alpha) P_{H}^{1 /(1-\alpha)} H .
$$

A parallel expression gives $\pi_{L}$. Balanced growth requires $\pi_{L}=\pi_{H}$; in this case, $A_{H}$ and $A_{L}$ grow at the same rate, the ratio $A_{H} / A_{L}$ is constant as are $J, P_{L}$ and $P_{H}$. Imposing $\pi_{L}=\pi_{H}$ in (52) and using (50) yields:

$$
\frac{A_{H}}{A_{L}}=\frac{1-J}{J}=\frac{H}{L} .
$$

Note that the equilibrium skill-bias is identical to that of (43) in the special case when $\sigma=2$. Further, (53) shows that the higher is the skill endowment of a country, the larger is the range of sectors using the skilled technology. This is a complete characterization of the equilibrium for fully integrated economies developing and selling technologies in their markets with full protection of IPRs and can be interpreted as a description of the collection of rich countries, here called the North.

Consider now Southern economies, where skilled labor is assumed to be relatively more scarce: $H^{S} / L^{S}<H^{N} / L^{N}$. Assume that intellectual property rights are not enforced in the South and that there is no North-South trade. It follows that intermediate producers located in the North cannot sell their goods or copyrights to firms located in the South, so that the relevant market for technologies is the Northern market only. Nonetheless, Southern producers can copy Northern innovations at a small but positive cost. As a consequence, no two firms in the South find it profitable to copy the same innovation and all intermediates introduced in the North are immediately copied (provided that the imitation cost is sufficiently small) and sold to Southern producers by a local monopolist. Under these assumptions, firms in the South take the technologies developed originating in the North as given and do not invest in innovation. ${ }^{30}$ This means

\footnotetext{
${ }^{30}$ Imitation can be explicitly modelled as an activity similar to innovation, but less costly. Assuming the cost of an innovation of type $z$ to decrease with the distance from the relevant technology frontier $A_{Z}^{N}$, as in Barro and Sala-i-Martin (1997), would yield very similar results.
} 
that both the North and the South use the same technologies, but $A_{H} / A_{L}=H^{N} / L^{N}$, i.e., the skill-bias is determined by the factor endowment of the North, since this is the only market for new technologies. Except for this, the other equilibrium conditions also apply to the South after substituting the new endowments, $H^{S}$ and $L^{S}$.

We are now ready to answer the following questions: are technologies appropriate for the skill endowment of the countries where they are developed? What happens to aggregate productivity if they are used in a different economic environment?

Simple differentiation on (51) establishes that $Y$ is maximized for $A_{H} / A_{L}=H / L$. This is exactly condition (53), showing that the equilibrium skill-bias is optimally chosen for the Northern skill composition. On the contrary, since factor abundance in the South does not affect the direction of technical change, new technologies developed in the North are inappropriate for the needs of the South. As a consequence, output per capita, $Y /(L+H)$ is greater in the North than in the South. The reason for these productivity differences is a technology-skill mismatch. To understand why, note that, from equation (50), $J^{S}>J^{N}$. Rewriting (53) as $A_{H} J^{N}=A_{L}\left(1-J^{N}\right)$ and inspecting equation (47) reveals that unskilled workers are employed in the North up to sector $J^{N}$, where they become as productive as skilled workers. This basic efficiency condition is violated in the South, where $A_{H} J^{S}>A_{L}\left(1-J^{S}\right)$. Because of its smaller skill endowment, the South is using low-skill workers in some sectors where high-skill workers would be more productive.

This result can help understand the existence of substantial differences in TFP across countries, even when the technology is common. In particular, Acemoglu and Zilibotti (2001) compare the predictive power of their model in explaining cross-country output differences with that of a comparable neoclassical model, where all countries have access to the same technologies and output is Cobb-Douglas in labor, human and physical capital. Their computations suggest that the proposed mechanism can account for one-third to one half of the total factor productivity gap between the United States and developing countries. Predictions on the pattern of North-South, cross-industry, productivity differences are also tested. Since the South uses the same technology $\left[A_{L}, A_{H}\right]$ as the rest of the world, but it has a higher relative price for skill-intensive goods, it follows that the value of productivity in LDCs relative to that of the North should be higher in skill-intensive sectors. The empirical analysis supports this prediction.

The view that countries adopt different technologies out of a world "menu", and that the choice of the appropriate technology depends on factor endowments, particularly on the average skill of the labor force, finds support in the analysis of Caselli and Coleman (2000). However, these authors also find that many poor countries choose technologies inside the world technology frontier, thereby suggesting that barriers to technology adoption may also be important to explain the low total factor productivity of these countries.

\subsection{Trade, Inequality and Appropriate Technology}

We have seen that directed technical change can help understand inequality, both within and between countries. Several authors have stressed that international trade is another important determinant of income distribution. For example, Wood (1994) argues that 
the higher competition with imports from LDCs may be responsible for the deterioration in relative wages of low-skill workers in the US in the past decades. Further, there is a widespread concern that globalization may be accompanied by a widening of income differences between rich and poor countries. Although the analysis of these issues goes beyond the scope of this paper, we want to argue that R\&D-driven endogenous growth models can fruitfully be used to understand some of the links between trade and inequality. In particular, we now show that trade with LDCs can have a profound impact on income distribution, beyond what is suggested by static trade theory, through its effect on the direction of technical change. By changing the relative prices and the location of production, international trade can change the incentives for developing innovations targeted at specific factors or sectors, systematically benefitting certain groups or countries more than others. A key assumption in deriving these results is that, as in the previous paragraph, LDCs do not provide an adequate protection of IPRs.

First, consider the effect of trade in the benchmark model of directed technical change. The analysis follows Acemoglu (2002, 2003a). Recall that the profitability of an innovation depends on its market size and the price of the goods it produces, as in equation (39). What happens to technology if we allow free trade in $Y_{L}$ and $Y_{H}$ between a skill-abundant North and a skill-scarce South? The market size for innovations does not change, because inventors continue to sell their machines in the North only. But trade, at first, will increases the relative price of skill-intensive goods in the North. To see this, note that trade generates a single world market with a relative price depending on the world supply of goods. Since skills are scarcer in the world economy than in the North alone, trade will increase the relative price of skill-intensive goods in the North (the opposite will happen in the South). In particular, world prices are now given by equation (41) using world endowments:

$$
\frac{P_{H}}{P_{L}}=\left(\frac{A_{H}}{A_{L}} \frac{H^{W}}{L^{W}}\right)^{-(1-\alpha) / \sigma} .
$$

This change in prices, for a given technology, makes skill-complement innovations more profitable and accelerates the creation of skill-complementary machines. Since, along the BG path, both types of innovations must be equally profitable and hence $\pi_{H}=\pi_{L}$, equation (39) shows that this process continues until the relative price of goods has returned to the pre-trade level in the North. Substituting equation (54) in (39) and imposing $\pi_{H}=\pi_{L}$, yields the new equilibrium skill bias of technology:

$$
\frac{A_{H}}{A_{L}}=\frac{L^{W}}{H^{W}}\left[\frac{H^{N}}{L^{N}}\right]^{\sigma} .
$$

Given that $H^{N} / L^{N}>H^{W} / L^{W}$, the new technology is more skill-biased and skilled workers in the North earn higher wages. The effect on the skill premium can be seen by substituting (55) in (42):

$$
\frac{w_{H}}{w_{L}}=\left[\frac{H^{N}}{L^{N}} \frac{L^{W}}{H^{W}}\right]\left[\frac{H^{N}}{L^{N}}\right]^{\sigma-2} .
$$


The effect of a move from autarky to free trade can be approximated by the elasticity of the skill premium to a change in $L^{W} / H^{W}$ computed at $L^{W} / H^{W}=L^{N} / H^{N}$ (that is, starting from the pre-trade equilibrium). Equation (56) shows this elasticity to be unity. Thus, if, for example, $L^{W} / H^{W}$ were $4 \%$ higher than $L^{N} / H^{N}$, the model would predict trade to raise the skill premium by the same $4 \%{ }^{31}$

Without technical change, instead, the reaction of the skill premium to a change in the perceived scarcity of factors due to trade depends on the degree of substitutability of skilled and unskilled workers. From equation (42), the elasticity of the skill premium to a change in $L / H$ would be $1 / \sigma$, less than in the case of endogenous technology as long as $\sigma>1$, i.e., when skilled and unskilled workers are gross substitutes. Therefore, with directed technical change and $\sigma>1$, trade increases the skill premium in the North by more than would otherwise be the case: for example, if the elasticity of substitution is 2 , the endogenous reaction of technical progress doubles the impact of trade on wage inequality.

Note that another direct channel through which trade can affect factor prices in models of endogenous technical change is by affecting the reward to innovation. If trade increases the reward to innovation (for example, through the scale effect) and the R\&D sector is skill-intensive relative to the rest of the economy, trade will naturally spur wage inequality. This mechanism is studied by Dinopoulos and Segerstrom (1999) in a quality-ladder growth model with no scale effects. ${ }^{32}$

What are the implications of trade opening for cross-country income differences? We have seen that trade induces a higher skill bias in technology; given the result of Acemoglu and Zilibotti (2001) that the excessive skill-complementarity of Northern technologies is a cause of low productivity in Souther countries, it may seem natural to conclude that trade would then increase productivity differences. However, this conclusion would be premature. In the absence of any barriers, trade equalizes the price of goods; given that the production functions adopted so far rule out complete specialization, this immediately implies that factor prices and sectoral productivity are also equalized. This does not mean that trade equalizes income levels; because of their different skill-composition, the North and the South will still have differences in income per capita, but nothing general can be said. ${ }^{33}$

The fact that trade generates productivity convergence crucially depends on factor prices being equalized by trade. Since factor price equalization is a poor approximation of reality, it is worth exploring the implications of models with endogenous technologies

\footnotetext{
${ }^{31}$ Borjas, Freeman and Katz (1997) show that $4 \%$ is a plausible estimate of the increase in the unskilled labor content of US trade with LDCs between 1980 and 1995. Therefore, this simple exercise may give a sense of how much of the roughly $20 \%$ increase in the US skill premium in the same period can be attributed to trade.

${ }^{32}$ Recently, other papers have suggested that trade between identical countries may as well increase skill premia through its effect on technology. See, for example, Epifani and Gancia (2002), Neary (2003) and Thoenig and Verdier (2003).

${ }^{33} \mathrm{~A}$ general result is that the endogenous response of technology makes trade less beneficial for LDCs than would otherwise be the case. This occurs because, after trade opening, the skill premium rises as a result of the induced skill-biased technical change. Given that the North is more skilled-labor abundant, it proportionally benefits more from a higher skill premium.
} 
when this property does not hold. A simple way of doing this is to add Ricardian productivity differences, so that trade opening leads to complete specialization. In this case, the endogenous response of technology to weak IPRs in LDCs becomes a force promoting productivity divergence. ${ }^{34}$ Further, trade with countries providing weak protection for IPRs may have an adverse effect on the growth rate of the world economy. These results, shown by Gancia (2003), can be obtained by modifying Acemoglu and Zilibotti (2001) as follows. First, we allow the elasticity of substitution between final goods to be larger than one: $Y=\left[\int_{0}^{1} y_{i}{ }^{(\epsilon-1) / \epsilon} d i\right]^{\epsilon /(\epsilon-1)}$, with $\epsilon>1$. Then, we assume that each good $y_{i}$ can be produced by competitive firms both in the North and the South, using sector-specific intermediates and labor:

$$
y_{i}=\left[(1-i) l_{i}^{S}\right]^{1-\alpha} \int_{0}^{A_{i}}\left(x_{i, v}^{S}\right)^{\alpha} d v+\left[i l_{i}^{N}\right]^{1-\alpha} \int_{0}^{A_{i}}\left(x_{i, v}^{N}\right)^{\alpha} d v .
$$

There are three important differences with respect to (45). First, $(1-i)$ and $i$ now capture Ricardian productivity differences between the North and South, implying that the North is relatively more productive in high index sectors. Second, intermediate goods are sector specific, not factor specific (there is now a continuum $[0,1]$ of technologies, not only two). Third, there is only one type of labor. Given that the endogenous component of technology $\left(A_{i}\right)$ is still assumed to be common across countries, the sectoral NorthSouth productivity ratio only depends on the Ricardian elements. The new implication is that countries specialize completely under free trade, as each good is only manufactured in the location where it can be produced at a lower cost.

The equilibrium can be represented by the intersection of two curves, as in Dornbusch et. al. (1977). For any relative wage, the first curve gives the range $[0, J]$ of goods efficiently produced in the South: $\frac{J}{1-J}=\frac{w^{N}}{w^{S}}$. The second curve combines trade balance and a BG research arbitrage condition, requiring profits to be equalized across sectors and countries. To find this, the model assumes that the owner of a patent can only extract a fraction $\lambda<1$ of the profits generated by its innovation in the South, so that $\lambda$ can be interpreted as an index of the strength of international IPRs protection. The trade balance plus the research arbitrage condition turn out to be (see Gancia, 2003):

$$
\frac{w^{N}}{w^{S}}=\lambda^{-\widetilde{\sigma}}\left[\frac{L^{S}}{L^{N}} \frac{\int_{J}^{1}(i)^{\widetilde{\sigma} /(1-\widetilde{\sigma})} d i}{\int_{0}^{J}(1-i)^{\widetilde{\sigma} /(1-\widetilde{\sigma})} d i}\right]^{1-\widetilde{\sigma}}
$$

with $\widetilde{\sigma} \equiv(1-\alpha)(\epsilon-1) \in(0,1) \cdot{ }^{35}$ As long as $\widetilde{\sigma}>0$ (i.e., $\epsilon>1$ ), the wage gap is decreasing in the degree of protection of IPRs in the South, $\lambda$. The reason is that weaker protection of IPRs shifts innovations out of Southern sectors and increases the relative productivity of the North. From the condition $\frac{J}{1-J}=\frac{w^{N}}{w^{S}}$, it is easily seen

\footnotetext{
${ }^{34}$ The idea that trade may magnify cross-country inequality was put forward by several economists. Some examples are Stiglitz (1970), Young (1991), Krugman and Venables (1995), Matsuyama (1996), Rodriguez-Clare (1996) and Ventura (1997).

$35 \widetilde{\sigma}<1$ guarantees balanced growth across sectors. $\widetilde{\sigma}>0$, i.e., an elasticity of substitution between goods greater than one, rules out immiserizing growth.
} 
that a weaker protection of IPRs in the South, by raising $w^{N} / w^{S}$, is accompanied by a reduction in sectors $[1-J]$ located in the North, because higher wages make the North less competitive. A second result emerges by calculating the growth rate of the world economy. In particular, Gancia (2003) shows the growth rate of the world economy to fall with $\lambda$ and approach zero if $\lambda$ is sufficiently low. The reason is that a lower $\lambda$ shifts innovation towards Northern sectors and, at the same time, induces the relocation of more sectors to the South, where production costs become lower. This, in turn, implies that a wider range of goods becomes subject to weak IPRs and hence, to a low innovation incentive.

\section{Complementarity in Innovation}

In the models described so far, innovation has no effect on the profitability of existing intermediate firms. This is a knife-edge property which descends from the specification of the final production technology, (3). In general, however, new technologies can substitute or complement existing technologies.

Innovation often causes technological obsolescence of previous technologies. Substitution is emphasized, in an extreme fashion, by Schumpeterian models such as Aghion and Howitt (1992). In such models, innovation provides "better of the same", i.e., more efficient versions of the pre-existing inputs. Growth is led by a process of creative destruction, whereby innovations do not only generate but also destroy rents over time. This has interesting implications for dynamics: the expectation of future innovations discourages current innovation, since today's innovators expect a short life of their rents due to rapid obsolescence. More generally, substitution causes a decline in the value of intermediate firms over time, at a speed depending on the rate of innovation in the economy.

There are instances, however, where new technologies complement rather than substitute old technologies. The market for a particular technology is often small at the moment of its first introduction. This limits the cash-flow of innovating firms, which initially pose little threat to more established technologies. However, the development of new compatible applications expands the market for successful new technologies over time, thereby increasing the profits earned by their producers. Rosenberg (1976) discusses a number of historical examples, where such complementarities were important. A classical example is the steam engine. This had been invented in the early part of the XVIIIth Century, but its diffusion remained very sporadic before a number of complementary innovations (e.g., Watt's separate condenser) made it competitive with the waterwheels, which remained widespread until late in the XIXth Century.

Complementarity in innovation raises interesting issues concerning the enforcement and design of intellectual property rights. For instance, what division of the surplus between basic and secondary innovation maximizes social welfare? This issue is addressed by Scotchmer and Green (1995) who construct a model where innovations are sequentially introduced, and the profits of major innovators can be undermined by subsequent derivative innovations. In this case, the threat of derivative innovations can reduce the incentive for firms to invest in major improvements in the first place. However, too strong a defense of the property right of basic innovators may reduce the incentive to 
invest in socially valuable derivative innovations. Scotchmer and Green (1995) show that the optimal policy in fact consists of a combination of finite breath and length of patents. Scotchmer (1996) instead argues that it may be optimal to deny patentability to derivative innovations, instead allowing derivative innovations to be developed under licensing agreements with the owner of the basic technology. More recently, Bessen and Maskin (2002) show that when there is sufficient complementarity between innovations (as in the case of the software industry), weak patent laws may be conducive to more innovation than strong patent laws. The reason is that while the incumbent's current profit is increased by strong patent laws, its prospect of developing future profitable innovation is reduced when patent laws inhibit complementary innovations.

While this literature focuses on the partial equilibrium analysis of single industries, complementarity in innovation also has implications on broader development questions. Multiple equilibria originating from coordination failures (of the type emphasized, in different contexts, by Murphy, Shleifer and Vishny, 1989, and Cooper and John, 1988) can arise when there is complementarity in innovation. Countries can get locked-in into an equilibrium with no technology adoption, and temporary big-push policies targeting incentives to adopt new technologies may turn out to be useful. ${ }^{36}$ One such example is Ciccone and Matsuyama (1996). In their model, multiple equilibria and poverty traps may arise from the two-way causality between the market size of each intermediate good and their variety: when the availability of intermediates is limited, final good producers are forced to use a labor intensive technology which, in turn, reduces the incentive to introduce new intermediates.

Young (1993) constructs a model where innovation expands the variety of both intermediate and final goods. New intermediate inputs are not used by mature final industries, and their market is initially thin. The expansion of the market for technologies over time creates complementarity in innovation. The details of this model are discussed in the remainder of this section. To this aim, we augment the benchmark model of section 2 with the endogenous expansion in the variety of final goods. ${ }^{37}$ Over time, innovative investments make new intermediate inputs available to final producers, as in Romer's model. However, as a by-product (spillover), they also generate an equivalent expansion of the set of final goods that can be produced. There are no property rights defined on the production of new final goods, and these are produced by competitive firms extraneous to the innovation process.

$A_{t}$ will now denote the measure of both final goods and intermediate goods available in the economy at $t$. Final products are imperfect substitutes in consumption, and the

\footnotetext{
${ }^{36}$ Interestingly, in models with complementarity in innovation, market economies may be stuck in no-growth traps that are inefficient in the sense that the optimal intertemporal allocation would require positive investment and growth. See, for example, Ciccone and Matsuyama (1999).

${ }^{37}$ Models featuring an expanding variety of final products include Judd (1985), Grossman and Helpman (1989, chapter 3) and, more recently, Xie (1998) and Funke and Strulik (2000). Here, we follow Young (1993) which, in turn, is close to Judd's paper.
} 
instantaneous utility function is: ${ }^{38}$

$$
V_{t}=\int_{0}^{A_{t}} \ln \left(C_{s, t}\right) d s,
$$

with total utility being

$$
U=\int_{0}^{\infty} e^{-\rho t} V_{t} d t
$$

This specification implies that consumers' needs grow as new goods become available. Suppose, for instance, that a measure $\varepsilon$ of new goods is introduced between time $t$ and $t+j$. At time $t$, consumers are satisfied with not consuming the varieties yet to be invented. However, at time $t+j$, the same consumers' utility would fall to minus infinity if they did not consume the new goods.

The productive technology for the $s^{\prime}$ th final good is given by

$$
Q_{s}=\left(\int_{0}^{\min [s \Theta, A]} x_{j, s}^{\alpha} d j\right)^{\frac{1}{\alpha}}
$$

where $\Theta \geq 1$ is a parameter. Note that labor is not used in the final goods production. First, to build the intuition in the simplest case, we maintain that all final goods are produced with the same technology employing all available varieties of intermediate inputs. More formally, we characterize the equilibrium in the limit case where $\Theta \rightarrow \infty$, so that $\min [s \Theta, A]=A$. This assumption will be relaxed later.

We use the "labor-for-intermediates" model introduced in section 2.2, where labor is used for research and intermediate production and the productivity of labor in intermediate production equals $A_{t}$. We choose the nominal wage as the numeraire. ${ }^{39}$ Hence, the profit of an intermediate producer can be expressed as:

$$
\pi=\frac{1-\alpha}{\alpha} \frac{x}{A}=\frac{1-\alpha}{\alpha} \frac{L-L_{x}}{A}
$$

Note that profits fall over time at the rate at which knowledge grows. In a BG equilibrium, the interest rate is constant and $A$ grows at the constant rate $\gamma$. Free entry implies:

$$
\int_{t}^{\infty} e^{-r \tau} \pi_{\tau} d \tau=\frac{1-\alpha}{\alpha} \frac{L-\gamma / \delta}{A_{t}(r+\gamma)} \leq \frac{1}{\delta A_{t}}
$$

where we have used the fact that $\gamma=\delta L_{x}$. Simplifying terms yields

$$
\frac{1-\alpha}{\alpha} \frac{\delta L-\gamma}{r+\gamma} \leq 1
$$

\footnotetext{
${ }^{38}$ This is the benchmark specification in Young (1993), where it is then extended to general CES preferences across goods. The logarithmic specification is analytically convenient because of the property that consumers spend an equal income share on all existing goods.

${ }^{39}$ Note that we cannot simply set the price of the final good as the numeraire, as there is an increasing variety of final goods.
} 
The intertemporal optimality condition for consumption also differs from the benchmark model. In particular, if $E$ denotes the total expenditure in final goods, the Euler condition is: ${ }^{40}$

$$
\frac{\dot{E}}{E}=r-\rho+\frac{\dot{N}_{t}}{N_{t}}
$$

In a BG equilibrium, the total expenditure on consumption goods is constant. Hence,

$$
r=\rho-\gamma
$$

This expression can be substituted into (61) to give a unique solution for $\gamma$. As long as growth is positive, we have

$$
\gamma=\delta L-\frac{\alpha \rho}{1-\alpha}
$$

which is almost identical to (15), except for the constant term $\alpha /(1-\alpha)$ being replaced by $1 / \alpha$. In the limit case considered so far $(\Theta \rightarrow \infty)$, the model is isomorphic to Romer (1990).

Next, we move to the general case where $\Theta \geq 1$ is finite. This implies that final producers cannot use the entire range of intermediate goods. In particular, an intermediate good indexed by $s$ cannot be used by "mature" final industries having an index $j$, such that $j<s / \Theta$. This assumption captures the idea that a technology mismatch develops over time between mature final good industries and new technologies. ${ }^{41}$

An important implication of this assumption is that, when introduced, a new technology (intermediate input) is only required by a limited number of final industries. Thus, the monopolist producing a new variety has a small cash-flow. This is especially true when the parameter $\Theta$ is small: as $\Theta \rightarrow 1$, there is no demand for a new intermediate good at the time of its first appearance. However, the market for technologies expands over time, as new final goods using "modern" technologies appear. This dynamic market size effect generates complementarity in the innovation process. An innovator is eager to see rapid technical progress, as this expands the number of users of the new technology.

Countering this effect, there is a process of "expenditure diversion" that reduces, ceteris paribus, the demand for each intermediate good. Over time, technical progress expands the number of intermediate inputs over which final producers spread their demand. As noted above, the total expenditure on final goods is constant in a BG equilibrium. Since final good firms make zero profits at all times, and intermediates are the only inputs, the total expenditure on the intermediate goods must also be constant. Therefore, an increase in $A$ dilutes the expenditure over a larger mass of intermediate goods, and reduces the profit of each existing intermediate firm. This effect generates substitution rather than complementarity in innovation.

The dynamic market size effect may dominate for young intermediate firms. But as a technology becomes more mature, the expenditure dilution effect takes over. Thus,

\footnotetext{
${ }^{40}$ See Young, 1993, p. 783 for the derivation of this Euler equation.

${ }^{41}$ In principle, it would seem natural to assume that new final goods do not use very old intermediate goods. Young (1993, p.780) argues that allowing for this possibility would not change the main results, but would make the analysis more involved.
} 
firms can go through a life-cycle: their profit flow increases over time at an earlier stage and decreases at a later stage.

We denote by $\pi\left(A_{\tau}, A_{t}\right)$ the profit realized at time $\tau$ by an intermediate producer who entered the market in period $t<\tau$. Solving the profit maximization problem for the intermediate monopolist, subject to the demand from final industries, leads to the following expression:

$$
\pi\left(A_{\tau}, A_{t}\right)=\frac{1-\alpha}{\alpha A_{\tau}}\left(L-L_{x}\right)\left(1+\frac{\gamma(\tau-t)-1}{\Theta}\right) .
$$

It is easily verified that as $\Theta \rightarrow \infty$, the solution becomes identical to (60), where nominal profits fall at the same rate as $A_{t}$.

Free-entry implies:

$$
\int_{t}^{\infty} e^{-r(\tau-t)} \pi\left(A_{\tau}, A_{t}\right) d \tau \leq \frac{1}{\delta A_{t}}
$$

Solving the integral on the left-hand side, using the Euler condition, $r+\gamma=\rho$, and simplifying terms yields the following equilibrium condition:

$$
f_{F E}(\gamma)=\frac{1-\alpha}{\alpha \rho^{2} \Theta}(\delta L-\gamma)(\gamma+\rho(\Theta-1)) \leq 1
$$

where all terms but $\gamma$ are parameters. For sufficiently large values of $\Theta$, i.e., when the market for new technology is large, $f_{F E}^{\prime}(\gamma)<0$ and the equilibrium is unique. However, if $\Theta<1+\delta L / \rho, f_{F E}(\gamma)$ is non-monotonic, and multiple equilibria are possible.

\section{FIGURE 2}

Figure 2 describes the three possible cases. As long as $\rho>\gamma$, which is a necessary and sufficient condition for the interest rate to be positive, $f_{F E}(\gamma)$ is increasing in $\Theta$. For a range of small $\Theta^{\prime}$ s, there is no equilibrium with positive innovation (lower curve). The only equilibrium is a point such as $\mathrm{X}^{\prime}$, featuring zero growth.

For an intermediate range of $\Theta$, we have $f_{F E}(\gamma)=1$ in correspondence of two values of $\gamma$ (intermediate curve). This implies that (for generic economies), there exist three equilibria, where equilibria such as point $X$ feature zero innovation and growth. Firms contemplating entry expect no expansion of the market size for new technologies. Furthermore, such market size is too small to warrant profitable deviations, and the expectation of no innovation is fulfilled in equilibrium. Equilibria such as point $Y$ are characterized by local complementarity in innovation: the expectation of higher future innovation and growth increases the value of new firms, stimulating current entry and 
innovation. In steady-state (BG), this implies a positive slope of the locus $f_{F E}(\gamma){ }^{42}$ Eventually, for sufficiently high growth rates, the diversion effect dominates. Thus, in an equilibrium like $Z$, the value of innovating firms depends negatively on the speed of innovation. $^{43}$

Finally, for a range of large $\Theta$ 's, substitution dominates throughout (upper curve). The initial market for new technologies is sufficiently large to make the expenditure diversion effect dominate the market size effect, even at low growth rates. The equilibrium is unique, and the solution is isomorphic to that of the benchmark model of expanding variety.

\section{Financial Development}

A natural way in which the expansion of the variety of industries can generate complementarities in the growth process is through its effects on financial markets. Acemoglu and Zilibotti (1997) construct a model where the introduction of new securities, associated with the development of new intermediate industries, improves the diversification opportunities available to investors. Investors react by supplying more funds, which fosters further industrial and financial development, generating a feedback. ${ }^{44}$ The model offers a theory of development. At early stages of development, a limited number of intermediate industries are active (due to technological nonconvexities), which limits the degree of risk-spreading that the economy can achieve. To avoid highly risky investments, agents choose inferior but safer technologies. The inability to diversify idiosyncratic risks introduces a large amount of uncertainty in the growth process. In equilibrium, development proceeds in stages. First, there is a period of "primitive accumulation" with a highly variable output, followed by take-off and financial deepening and finally, steady growth. Multiple equilibria and poverty traps are possible in a generalized version of the model.

The theory can explain why the growth process is both slow and highly volatile at early stages of development, and stabilizes as an economy grows richer. Evidence of this pattern can be found in the accounts of pre-industrial growth given by a number of historians, such as Braudel (1979), North and Thomas (1973) and DeVries (1990). For instance, in cities such as Florence, Genoa and Amsterdam, prolonged periods of prosperity and growth have come to an end after episodes of financial crises. Interestingly, these large set-backs were not followed (as a neoclassical growth model would instead

\footnotetext{
${ }^{42}$ As mentioned above, firms go through a life-cycle here. When a new technology is introduced, the profit flow of an innovating firm is small. As time goes by, the expenditure diversion effect becomes relatively more important. The value of a firm upon entry is the PDV of its profit stream. Local complementarity occurs if, for a particular $\gamma$, profits increase at a sufficiently steep rate in the earlier part of the firm's life-cycle.

${ }^{43}$ If the expectational stability of the equilibria in the sense of Evans and Honkapohja (2001) is tested, equilibria such as point $Y$ are not found to be E-stable, while equilibria such as $X$ and $Z$ are stable. See the discussion in section 7.2.

${ }^{44}$ This paper is part of a recent literature on the two-way relationship between financial development and growth. This includes Bencivenga and Smith (1991), Greenwood and Jovanovic (1990) and Zilibotti (1994). In none of these other papers does financial development take the form of an expansion in the "variety" of assets.
} 
predict) by a fast recovery but, rather, by long periods of stagnation. Similar phenomena are observed in the contemporary world. Acemoglu and Zilibotti (1997) document robust evidence of increases in GDP per capita being associated with large decreases in the volatility of the growth process. It has also been documented that higher volatility in GDP is associated with lower growth (Ramey and Ramey, 1995).

We here describe a simplified version of the model. Time is discrete. The economy is populated by overlapping generations of two-period lived households. The population is constant, and each cohort has a unit mass $(L=1)$. There is uncertainty in the economy, which we represent by a continuum of equally likely states $s \in[0,1]$. Agents are assumed to consume only in the second period of their lives. ${ }^{45}$ Their preferences are parameterized by the following (expected) utility function, inducing unit relative risk aversion:

$$
E_{t} U\left(c_{t+1}\right)=\int_{0}^{1} \log \left(c_{t+1}^{s}\right) d s .
$$

The production side of the economy consists of a unique final good sector, and a continuum of intermediate industries. The final good sector uses intermediate inputs and labor to produce final output. Output in state $s$ is given by the following production function:

$$
Y_{s, t}=\left(x_{s, t-1}+x_{\Phi, s, t-1}\right)^{\alpha} L^{1-\alpha} .
$$

The term in brackets is "capital", and it is either produced by a continuum of intermediate industries, each producing some state-contingent amount of output $\left(x_{s}\right)$, or a separate sector using a "safe technology" $\left(x_{\Phi}\right)$. The measure of the industries with a state-contingent production, $A_{t}$, is determined in equilibrium, and $A_{t}$ can expand over time, like in Romer's model, but it can also fall. Moreover, $A_{t} \in[0,1]$, i.e., the set of inputs is bounded.

In their youth, agents work in the final sector and earn a competitive wage, $w_{s, t}=$ $(1-\alpha) Y_{s, t}$. At the end of this period, they take portfolio decisions: they can place their savings in a set of risky securities $\left(\left\{F_{i}\right\}_{i \in\left[0, A_{t}\right]}\right)$, consisting of state-contingent claims to the output of the intermediate industries or, in a safe asset $(\phi)$, consisting of claims to the output of the safe technology. After the investment decisions, the uncertainty unravels, the security yields its return and the amount of capital brought forward to the next period is determined. The capital is then sold to final sector firms and fully depreciates after use. Old agents consume their capital income and die.

Intermediate industries use final output for production. An intermediate industry $i \in\left[0, A_{t}\right]$ is assumed to produce a positive output only if state $s=i$ occurs. In all other states of nature, the firm is not productive. Moreover, the $i$-th industry is only productive if it uses a minimum amount of final output, $M_{i}$, where

$$
M_{i}=\max \left\{0, \frac{D}{(1-x)}(i-x)\right\},
$$

with $x \in(0,1)$. This implies that some intermediate industries require a certain minimum size, $M_{i}$, before being productive. In particular, industries $i \leq x$ have no minimum

\footnotetext{
${ }^{45}$ This is for simplicity. Acemoglu and Zilibotti (1997) assume that agents consume in both periods. It is also possible to study the case of a general CRRA utility function.
} 
size requirement, and for the rest of the industries, the minimum size requirement increases linearly with the index $i$.

To summarize, the intermediate technology is described by the following production function:

$$
x_{i, s}=\left\{\begin{array}{cc}
R F_{i} & \text { if } i=s \text { and } F_{i} \geq M_{i} \\
0 & \text { otherwise }
\end{array} .\right.
$$

Since there are no start-up costs, all markets are competitive. Thus, firms retain no profits, and the product is entirely distributed to the holders of the securities. The $j^{\prime}$ th security entitles its owner to a claim to $R$ units of capital in state $j$ (as long as the minimum size constraint is satisfied, which is always the case in equilibrium), and otherwise to nothing. Savings invested in the "safe technology" give the return

$$
x_{\Phi, s}=r \phi, \forall s \in[0,1],
$$

where $r<R$. Thus, one unit of the safe asset is a claim to $r$ units of capital in all states of nature.

Since the risky securities yield symmetric returns, and there is safety in numbers, it is optimal for risk-averse agents to hold a portfolio containing all available securities in equal amounts. More formally, the optimal portfolio decision features $F_{i}=F$, for all $i \in\left[0, A_{t}\right]$. We refer to this portfolio consisting of an equal amount of all traded risky securities as a balanced portfolio.

If $A_{t}=1$, a balanced portfolio of risky securities bears no risk, and first-order dominates the safe investment. However, due to the presence of technological non-convexities (minimum size requirements), not all industries are in general activated. When $A_{t}<1$, the inferior technology is safer, and there is a trade-off between risk and productivity. In this case, the optimal investment decision of the representative saver can be written as:

$$
\max _{\phi_{t, F_{t}}} A_{t} \log \left[\rho_{G, t+1}\left(R F_{t}+r \phi_{t}\right)\right]+\left(1-A_{t}\right) \log \left[\rho_{B, t+1}\left(r \phi_{t}\right)\right]
$$

subject to:

$$
\phi_{t}+A_{t} F_{t} \leq w_{t}
$$

$\rho_{\tilde{s}, t+1}$ denotes the rate of return of capital, which is taken as parametric by agents, and does not affect the solution of the program. ${ }^{46}$ Agents also take $A_{t}$, i.e., the set of securities offered, as parametric.

\footnotetext{
${ }^{46}$ In equilibrium:

$$
\rho_{G, t+1}=\alpha\left(R F_{t}+r \phi_{t}\right)^{\alpha-1}
$$

and

$$
\rho_{B, t+1}=\alpha\left(r \phi_{t}\right)^{\alpha-1} .
$$

$\rho_{G, t+1}$ applies in the "good state", i.e., when the realized state is $i \leq A_{t}$, while $\rho_{B, t+1}$ is the marginal product of capital in the "bad" state, when the realized state is $i>A_{t}$ and no risky investment pays off.
} 
Simple maximization yields:

$$
\begin{aligned}
\phi_{t}^{*} & =\frac{\left(1-A_{t}\right) R}{R-r A_{t}} w_{t}, \\
F_{i, t}^{*} & =\left\{\begin{array}{cc}
F\left(A_{t}\right) \equiv \frac{R-r}{R-r A_{t}} w_{t}, & \forall i \leq A_{t} \\
0 & \forall i>A_{t}
\end{array} .\right.
\end{aligned}
$$

\section{FIGURE 3}

Figure 3 expresses the demand for each risky asset, $F\left(A_{t}\right)$ (FF schedule), as a function of the measure of intermediate industries which are active. The FF schedule is upward sloping, implying that there is complementarity in the demand for risky assets: the demand for each asset grows with the variety of intermediate industries.

Complementarity arises because the more active are intermediate industries, the better is risk-diversification. Thus, as $A_{t}$ increases, savers shift their investments away of the safe asset into high-productivity risky projects (the "stock market"). Such complementarity hinges on risk aversion being sufficiently high. ${ }^{47}$ In general, similar to Young (1993), an increase in $A$ creates two effects. On the one hand, investments in the stock market become safer because of better diversification opportunities, which induces complementarity. On the other hand, investments are spread over a larger number of assets, inducing substitution. With sufficiently high risk aversion, including the unit CRRA specification upon which we focus, the first effect dominates.

The equilibrium measure of active industries, $A_{t}^{*}$, is determined (as long as $A^{*}<1$ ) by the following condition:

$$
F\left(A_{t}^{*}\right)=M_{A_{t}^{*}} .
$$

In figure 3, the equilibrium is given by the intersection of schedules FF and MM, where the latter represents the distribution of minimum size requirements across industries. Intuitively, $A_{t}^{*}$ is the largest number of industries for which the technological non-convexity can be overcome, subject to the demand of securities being given by (71). ${ }^{48}$

Growth increases wage income and the stock of savings over time. In equilibrium, this induces an expansion of the intermediate industries, $A_{t}^{*}$. This can once more be seen

\footnotetext{
${ }^{47}$ Suppose agents were risk averse, but only moderately so. Suppose, in particular, that they were so little risk-averse that they would decide not to hold any safe asset in their portfolio. Then, an expansion in the set of risky securities would induce agents to spread their savings (whose total amount is predetermined) over a larger number of assets. In this case, assets would be substitutes rather than complements.

${ }^{48}$ Acemoglu and Zilibotti (1997) show the laissez-faire portfolio investment to be inefficient. Efficiency would require more funds to be directed to industries with large non-convexities, i.e., agents not holding a balanced portfolio. The inefficiency is robust to the introduction of a rich set of financial institutions.
} 
in Figure 3: growth creates an upward shift of the FF schedule, causing the equilibrium to move to the left. Therefore, growth triggers financial development. In particular, when the stock of savings becomes sufficiently large, the financial market is sufficiently thick to allow all industries to be active. In the case described by the dashed curve, FF', the economy is sufficiently rich to afford $A_{t}^{*}=1$. The inferior safe technology is then abandoned. Financial development, speeds up growth by channelling investments towards the more productive technology.

The stochastic equilibrium dynamics of GDP can be explicitly derived:

$$
Y_{t+1}=\left\{\begin{array}{cc}
F_{B}\left(Y_{t}\right)=\left((1-\alpha) \frac{r\left(1-A_{t}^{*}\right)}{R-r A_{t}^{*}} R Y_{t}\right)^{\alpha} & \text { prob. } 1-A_{t}^{*} \\
F_{G}\left(Y_{t}\right)=\left((1-\alpha) R Y_{t}\right)^{\alpha} & \text { prob. } A_{t}^{*}
\end{array},\right.
$$

where $A_{t}^{*}=A\left(Y_{t-1}\right) \leq 1$ is the equilibrium measure of intermediate industries, such that $A^{\prime} \geq 0 .{ }^{49}$ The first line corresponds to the case of a "bad realization" at time $t$, such that $s \in\left(A_{t}^{*}, 1\right]$. In this case, none of the active intermediate industries turned out to pay-off at time $t$, and capital at time $t+1$ is only given by the return of the safe technology. The second line corresponds to the case of a "good realization" at $t$, such that $s \in\left[0, A_{t}^{*}\right]$. In this case, the risky investment paid off at time $t$, and capital and output are relatively large at time $t+1$. Note that the probability of a good realization increases with the level of development, since $A^{\prime}\left(Y_{t-1}\right) \geq 0$ (with strict inequality as long as $\left.A^{*}<1\right)$.

\section{FIGURE 4}

Figure 4 describes the dynamics. The two schedules represent output at time $t+1$ as a function of output at time $t$ conditional on good news $\left(F_{G}\left(Y_{t}\right)\right)$ and bad news $\left(F_{B}\left(Y_{t}\right)\right)$, respectively. At low levels of capital $\left(Y \leq Y_{L}\right)$, the marginal product of capital is very high, which guarantees that growth is positive, even conditional on bad news. In the intermediate range where $Y \in\left[Y_{L}, Y_{M}\right]$, growth only occurs if news is good, since $F_{B}\left(Y_{t}\right)<Y_{t}<F_{G}\left(Y_{t}\right)$. The threshold $Y_{L}$ is not a steady-state; however, it is a point around which the economy will spend some time. When the initial output is below $Y_{L}$, the economy necessarily grows towards it. When it is above $Y_{L}$, output falls back whenever bad news occurs. So, in this region, the economy is still exposed to undiversified risks, and experiences fluctuations and set-backs. Finally, for $Y \geq Y_{M}$, there are enough savings in the economy to overcome all technological non-convexities. When the economy enters this region, all idiosyncratic risks are removed, and the economy

\footnotetext{
${ }^{49}$ Acemoglu and Zilibotti (1997) derive a closed-form solution for $A_{t}^{*}$ that we do not report here.
} 
deterministically converges to $Y_{H} \cdot{ }^{50}$

\section{FIGURE 5}

Note that it may appear as if, in the initial stage, countries striving to take off do not grow at a sustained rate during long periods. The demand for insurance takes the form of investments in low-productivity technologies, and poor economies tend to have low total factor productivity and slow growth.

In the case described by Figure 4, the economies "almost surely" converge to a unique steady-state. Different specifications of the model can, however, lead to less optimistic predictions. With higher risk aversion, for instance, traps can emerge, as in the example described in Figure 5. An economy starting with a GDP in the region [0, $\left.Y_{M M}\right)$ would never attain the high steady-state $Y_{H}$, and would instead perpetually wander in the trapping region $\left[0, Y_{L L}\right]$. Conversely, an economy starting above $Y_{M}$ would certainly converge to the high steady-state, $Y_{H}$. Finally, the long-run fate of an economy starting in the region $\left[Y_{M M}, Y_{M}\right]$ would be determined by luck: an initial set of positive draws would bring this economy into the basin of attraction of the good equilibrium. A single set-back, however, would forever jeopardize its future development. ${ }^{51}$

The model can be extended in a number of directions. A two-country extension shows that international capital flows may lead to divergence, rather than convergence between economies. This result is due to the interplay between two forces: first, decreasing returns to capital would tend to direct foreign investments towards poorer countries, as in standard neoclassical models. Second, the desire to achieve better diversification pushes investments towards thicker markets. The latter force tends to prevail at some earlier stages of the development process. So, poor countries suffer an outflow of capital, which spills over to lower income and wages for the next generation, thereby slowing down the growth process. The analysis of capital flows, financial integration and financial crises in the context of similar models is further developed in recent papers by Martin and Rey (2000, 2001 and 2002). A different extension of the model is pursued by Cetorelli (2002) who shows that the theory can account for phenomena such as "club convergence", economic miracles, growth disasters and reversals of fortune.

\footnotetext{
${ }^{50}$ That the economy converges "almost surely" to a steady-state where all risk is diversified away only occurs under parameter restrictions ensuring that $Y^{S S}>Y^{1}$. Although the model presented here is neoclassical and features zero growth in the long run, it is possible to augment it with spillover of the learning-by-doing type, as in Romer (1986), and make it generate self-sustained growth.

${ }^{51}$ Consider, for instance, the limit case where agents are infinitely risk-averse. In this case, agents refuse to invest in the stock-market as long as this entails some uncertainty, i.e., as long as there are not enough savings in the economy to open all industries. Thus, an economy starting above $Y_{M}$ converges to $Y_{H}$, while an economy starting below $Y_{M}$ converges to $Y_{L}$, and is stuck in a poverty trap.
} 
Recent empirical studies analyze implications of the theory about the patterns of risksharing and diversification. Kalemli-Ozcan et al. (2001, 2003) document that regions with access to better insurance through capital markets can afford a higher degree of specialization. Using cross-country data at different levels of disaggregation, Imbs and Wacziarg (2003) find robust evidence of sectoral diversification increasing in GDP. However, their findings also suggest that, at a relatively late stage of the development process, the pattern reverts and countries once more start to specialize. This tendency for advanced countries to become more specialized as they grow can be explained by factors emphasized by the "new economic geography" literature (Krugman, 1991), from which the theory described in this section abstracts, such as agglomeration externalities and falling transportation costs.

\section{Endogenous Fluctuations}

In the models reviewed so far, the economies converge in the long run to balanced-growth equilibria characterized by linear dynamics. Growth models with expanding variety and technological complementarities can, however, generate richer long-run dynamics, including limit cycles. In this section, we review two such models.

In the former, based on Matsuyama (1999), cycles in innovation and growth arise from the deterministic dynamics of two-sector models with an endogenous market structure. The theory can explain some empirical observations about low-frequency cycles, and their interplay with the growth process. In particular, it predicts that waves of rapid growth mainly driven by "factor accumulation" are followed by spells of innovationdriven growth. Interestingly, these latter periods are characterized by lower investments and slower growth. This is consistent with the findings of Young (1995) that the growth performance of East-Asian countries was mainly due to physical and human capital accumulation, while there was little total factor productivity (TFP) growth. According to Matsuyama's theory, the observation of low TFP growth should not lead to the pessimistic conclusions that growth is destined to die-off. Rather, rapid factor accumulation could set the stage for a new phase of growth characterized by more innovative activity. The predictions of this theory bear similarities to those of models with General Purpose Technologies (GPT), e.g., Helpman (1999) and Aghion and Howitt (1998, ch. 8). For instance, they predict that a period of rapid transformation and intense innovation (e.g., the 1970's) can be associated with productivity slowdowns. However, GPT-based theories rely on the exogenous arrival of new "fundamental" innovations generating downstream complementarities. In contrast, cycles in Matsuyama (1999) are entirely endogenous. ${ }^{52}$

\footnotetext{
${ }^{52}$ Cyclical equilibria can also emerge in Schumpeterian models, due to the dynamic relationship between innovative investments and creative distruction. An example is the seminal contribution of Aghion and Howitt (1992). More recently, Francois and Lloyd Ellis (2003) construct a Schumpeterian model where entrepreneurs can decide to time the implementation of innovations (similarly to Shleifer, 1988). In this model, agents time the implementation so as to profit from buoyant demand and maximize the duration of their leadership. This mechanism leads to a clustering of innovations and endogenous cycles. While this model can explain some features of fluctuations at business cycle frequencies, Matsuyama's model is better suited for the analysis of long waves.
} 
In the latter model, based on Evans et al. (1998), cycles in innovation and growth are instead driven by expectational indeterminacy. The mechanism in this paper is different, as cycles hinge on multiple equilibria and sunspots. Some main predictions are also different: contrary to Matsuyama (1999), the equilibrium features a positive comovement of investments and innovation. The main contribution of the paper is to show that cycles can be learned by unsophisticated agents holding adaptive expectations. Thus, the predictive power of the theory does not rest on the assumption that agents' expectations are rational and that agents can compute complicated dynamic equilibria.

\subsection{Deterministic Cycles}

Matsuyama (1999) presents a model of expanding variety where an economy can perpetually oscillate in equilibrium between periods of innovation and periods of no innovation. Cycles arise from the deterministic periodic oscillations of two state variables (physical capital and knowledge). Unlike the model that will be discussed in the next section, the equilibrium is determinate and there are no multiple steady-states.

More specifically, the source of the oscillatory dynamics is the market structure of the intermediate goods market. Monopoly power is assumed to be eroded after one period. The loss of monopoly power is due to the activity of a competitive fringe which can copy the technology with a one-period lag. In every period, new industries are monopolized, while mature industries are competitive. The profits of innovators depend on the market structure of the intermediate sector. The larger is the share of competitive industries in the intermediate sector, the lower is the profit of innovative firms, since competitive industries sell larger quantities and charge lower prices. In periods of high innovation, a large share of industries are monopolized, which increases the profitability of innovation, thereby generating a feedback. In these times, investment in physical capital is low due to the crowding out from the research activity. Conversely, times of low innovation are times of high competition, since old monopolies lose power and there are few new firms. Thus, the rents accruing to innovative firms are small. In these periods, savings are invested in physical capital, and while innovation is low, the high accumulation of physical capital creates the conditions for future innovation to be profitable.

Time is discrete. The production of final goods is as in (3), where we set $L_{y}=$ $L=1$. Intermediate goods are produced using physical capital, with one unit of capital producing one unit of intermediate product, $x$. Innovation also requires capital, with a requirement of $\mu$ units of capital per innovation. Monopoly power is assumed to last one period only. Therefore, in period $t$, all intermediate inputs with an index $z \in\left[0, A_{t-1}\right]$ are competitively priced, whereas all those with an index $z \in\left[A_{t-1}, A_{t}\right]$ are monopolistically priced. The prices of competitive and non-competitive varieties are $p_{t}^{c}=r_{t}$ and $p_{t}^{m}=r_{t} / \alpha$, respectively, where the superscript $h \in\{c, m\}$ denotes the market structure. The relative demand for two varieties $x_{t}^{c}$ and $x_{t}^{m}$ must be:

$$
\frac{x_{t}^{c}}{x_{t}^{m}}=\left(\frac{p_{t}^{c}}{p_{t}^{m}}\right)^{-\frac{1}{1-\alpha}}=\alpha^{-\frac{1}{1-\alpha}} .
$$

The one-period monopoly profit is $\pi_{t}=p_{t}^{m} x_{t}^{m}-r_{t} x_{t}^{m}=x_{t}^{m} r_{t}(1-\alpha) / \alpha$. Since patents expire after one period, $\pi_{t}$ is also the value of a monopolistic firm at the beginning 
of period $t$. Therefore, free-entry implies:

$$
\frac{1-\alpha}{\alpha} x_{t}^{m} \leq \mu
$$

with equality holding when innovation is positive.

Capital is assumed to fully depreciate after each period. The stock of capital can be allocated to research or intermediate production, subject to the following resource constraint:

$$
K_{t-1}=A_{t-1} x_{t}^{c}+\left(A_{t}-A_{t-1}\right)\left(x_{t}^{m}+\mu\right)
$$

implying:

$$
A_{t}-A_{t-1}=A_{t-1} \max \left\{0, \frac{(1-\alpha) K_{t-1}}{\mu A_{t-1}}-\alpha^{-\frac{\alpha}{1-\alpha}}\right\},
$$

where we have used (73) and (74) to eliminate $x_{t}^{c}$ and $x_{t}^{m}$. As shown by (75), there exists a threshold to the capital-knowledge ratio that triggers positive innovation. In particular, innovation occurs if $K_{t-1} / A_{t-1} \geq \alpha^{-\frac{\alpha}{1-\alpha}}(1-\alpha)^{-1} \mu \equiv k_{L}$. If $K_{t-1} / A_{t-1}<k_{L}$, then, all capital is allocated to intermediate production, all intermediate industries are competitive and final production is given by the standard neoclassical Cobb-Douglas technology:

$$
Y_{t}=A_{t-1}^{1-\alpha} K_{t-1}^{\alpha}
$$

In this case, an economy is said to be in a "Solow regime", with decreasing returns to capital. Since there is no investment in innovation, $A$ is constant and the dynamics has a neoclassical character. In contrast, if $K_{t-1} / A_{t-1} \geq k_{L}$, then a positive share of the capital stock is allocated to innovation and final production equals:

$$
Y_{t}=A_{t-1}\left[\alpha^{-\frac{1}{1-\alpha}} \frac{\alpha}{1-\alpha} \mu\right]^{\alpha}+\left(A_{t}-A_{t-1}\right)\left[\frac{\alpha}{1-\alpha} \mu\right]^{\alpha}
$$

Using (75) and simplifying terms, this equation can be written as:

$$
Y_{t}=D K_{t-1}
$$

where $D \equiv\left(k_{L}\right)^{-(1-\alpha)}$. In this case, the returns to capital are constant, like in endogenous growth models, and the economy is said to be in a "Romer regime". ${ }^{53}$

For tractability, we assume a constant savings rate, implying that $K_{t}=s Y_{t} .{ }^{54}$ Define $k_{t}=k_{L}^{-1} \cdot K_{t} / A_{t}$ as the (adjusted) capital-to-knowledge ratio. Then, standard algebra using (75), (76) and (77) establishes the following equilibrium law of motion:

$$
k_{t}=f\left(k_{t-1}\right)=\left\{\begin{array}{cl}
s D k_{t-1}^{\alpha} & \text { if } k_{t-1}<1 \\
\frac{s D k_{t-1}}{1+\alpha^{-} \frac{\alpha}{1-\alpha}\left(k_{t-1}-1\right)} & \text { if } k_{t-1} \geq 1
\end{array} .\right.
$$

\footnotetext{
${ }^{53}$ Zilibotti (1995) finds similar dichotomic equilibrium dynamics in a one-sector model with learningby-doing spillovers. Economies may converge to a stationary steady-state with "Solow dynamics" or embark on a virtuous path of "Romer dynamics" with self-sustained growth. Cycles cannot arise in equilibrium, while multiple self-fulfilling prophecies exist.

${ }^{54}$ Matsuyama (2001) relaxes this restriction and characterizes equilibrium by a second-order difference equation. Some of the main results, like the existence of a period-2 cycle, survive this generalization.
} 
The mapping $k_{t}=f\left(k_{t-1}\right)$ has two fixed points. The first is $k=0$, the second can either be $k=(s D)^{\frac{1}{1-\alpha}} \equiv \hat{k}_{1}$, if $s D \leq 1$, or $k=1+\alpha^{\frac{\alpha}{1-\alpha}}(s D-1) \equiv \hat{k}_{2}$, if $s D \geq 1$. In the former case, the fixed point lies in the range of the "Solow regime", while in the latter, it lies in the range of the "Romer regime". ${ }^{55}$

Three cases are possible:

1. If $s D \leq 1$, the economy converges monotonically to $k=\hat{k}_{1}$. In this case, the economy never leaves the Solow regime, and there are no innovative investments. The neoclassical dynamics converge to a stagnating level of GDP per capita.

2. If $s D>\max \left\{1, \alpha^{-\frac{\alpha}{1-\alpha}}-1\right\}$, then capital first monotonically accumulates in the Solow regime, with no innovation. The economy overcomes the development threshold, $k=1$ in finite time, and the process of innovation starts thereafter. Eventually, the economy converges to the BG equilibrium $\hat{k}_{2}$ in an oscillatory fashion. In the BG, capital and knowledge are accumulated at the same positive rate, and income per capita grows over time.

3. if $s D \in\left(1, \alpha^{-\frac{\alpha}{1-\alpha}}-1\right.$ ], the economy does not converge asymptotically to any BG equilibrium, and perpetually oscillates in the long run between the Solow- and the Romer-regime. This case is described by Figure 6. On the one hand, there is no steady-state in the Solow-regime, which rules out that the economy can be trapped in a stable equilibrium with no innovation. On the other hand, the steady-state $\hat{k}_{2}$ is locally unstable and cannot be an attractor of the dynamics in itself. Instead, there exists a period-2 cycle, such that one of the periodic points lies in the Solow regime $\left(k_{S}\right)$, while the other lies in the Romer regime $\left(k_{R}\right){ }^{56}$ The period-2 cycle is not necessarily stable, and if it is unstable, the economy can converge to cycles of higher periodicity or feature chaos. A general property of the dynamics is that the economy necessarily enters the region $I_{a b s}=[f(f(1)), f(1)]$ (shaded in figure $6)$, and never escapes from it. ${ }^{57}$

\section{FIGURE 6}

${ }^{55}$ It is easily verified that $f^{\prime}(0)>1, f^{\prime}\left(\hat{k}_{1}\right)=\alpha \in(0,1)$, and $f^{\prime}\left(\hat{k}_{2}\right)=-\left(\alpha^{-\frac{\alpha}{1-\alpha}}-1\right) /(s D)$, where $f^{\prime}\left(\hat{k}_{2}\right) \in(-1,0)$ if $s D>\alpha^{-\frac{\alpha}{1-\alpha}}-1$ and $f^{\prime}\left(\hat{k}_{2}\right)<-1$ if $s D \in\left(1, \alpha^{-\frac{\alpha}{1-\alpha}}-1\right)$. These properties are used to establish the results discussed below.

${ }^{56}$ A period-2 cycle exists if, given a mapping $x_{t+1}=f\left(x_{t}\right), f(f()$.$) has fixed points other than the$ fixed point of $f($.$) . A sufficient condition is that (i) f($.$) is continuous, (ii) there exists a closed, finite$ interval, $I$, such that $f(I) \subset I$ and (iii) $f($.) has an unstable fixed point. (i) and (iii) are clearly satisfied; (iii) is established in the next footnote for the interval $I_{a b s}$.

${ }^{57}$ To prove this result, two properties of the mapping need to be shown. First, $f(\cdot)$ must be unimodal, i.e., (i) $f($.$) must be continuous; (ii) f($.$) must be increasing in some left-hand neighborhood of 1$ and decreasing in some right-hand neighborhood of 1 . Second, it must be the case that $f(f(1))<1$. That $f$ is unimodal is immediate by inspection. After some algebra, it can also be proved that $f(f(1))<1$. 
In the case described by Figure 6, the model predicts that a poor economy would first grow through capital accumulation, and eventually enter the absorbing region $I_{a b s}$. Then, there is an alternance of periods of innovation and periods of no innovation. GDP per capita grows on average, but at a non-steady rate, and there are cycles in the innovative activity. Interestingly, output and capital grow more quickly in periods of no innovation (Solow regime) than in periods of high innovation (Romer regime). Another implication is that if an economy grows quickly, but has a low TFP growth, this does not imply that growth will die-off. Rather, fast capital accumulation can create the conditions for future waves of innovation, and viceversa.

\subsection{Learning and Sunspots}

Evans et al. (1998) propose the following generalization of the technology (3) for final production:

$$
Y=L^{1-\alpha}\left[\int_{0}^{A} x_{j}^{\zeta} d j\right]^{\phi},
$$

where $\zeta \phi=\alpha$. This specification encompasses the technology (3), in the case of $\phi=1$, and allows intermediate inputs to be complements or substitutes. They focus on the case of complementarity $(\phi>1)$, and show that in this case, the equilibrium can feature multiple steady states, expectational indeterminacy and sunspots. They emphasize the possibility of equilibria where the economy can switch stochastically between periods of high and low growth.

Time is discrete, and intermediate firms rent physical capital from consumers to produce intermediate goods. One unit of capital is required per unit of intermediate good produced. Capital is assumed not to depreciate. The resource constraint of this economy is:

$$
Y_{t}=C_{t}+K_{t} \cdot \chi\left(\frac{K_{t+1}-K_{t}}{K_{t}}\right)
$$

where $\chi($.$) is a function such that \chi^{\prime}>0, \chi^{\prime \prime} \geq 0$. If there are no costs of adjustment, then, $\chi(x)=x$. If $\chi^{\prime \prime}>0$, there are convex costs of adjustments.

By proceeding as in section 2, we can characterize the equilibrium of the intermediate industry. ${ }^{58}$ The profit of intermediate producers, in particular, turns out to be:

$$
\pi=\Omega A^{\xi}\left(r p_{K}\right)^{\frac{\alpha}{\alpha-1}}
$$

where $\xi \equiv(\phi-1) /(1-\alpha)$ and $\Omega \equiv(1-\zeta) \zeta^{\frac{1+\alpha}{1-\alpha}} \phi^{\frac{1}{1-\alpha}} L$ are two positive constant. We denote by $p_{K}$ the relative price of capital, expressed in terms of the consumption good numeraire. If there are no adjustment costs, then, $p_{K}=1$ while, in general, $p_{K}=\chi^{\prime}($.$) .$ Note that profits increase with $A$, as long as $\phi>1$.

\footnotetext{
${ }^{58}$ Note that firms rent, and do not own, their capital stock. Adjustment costs are borne at the aggregate level, not at the level of each decision unit. Therefore, it continues to be legitimate to write the profit maximization problem for intermediate producers as a sequence of static maximization problems.
} 
Two technical assumptions ensure that the model has BG properties. First, the design of a new good requires $A_{t}^{\xi}$ units of output. Second, innovative investments incurred at $t$ only give the first profit in period $t+1$. Free entry then implies:

$$
\sum_{s=0}^{\infty} \frac{\pi_{t+s}}{(1+r)^{s+1}} \leq p_{K, t} A_{t}^{\xi} .
$$

In a BG equilibrium, consumption and capital grow at the common rate, $\gamma$. When $\phi>1$, this rate exceeds the growth rate of technical knowledge, $\gamma_{A} \equiv A_{t+1} / A_{t}$. In particular, it can be shown that $\gamma=\gamma_{A}^{1+\xi}$. Substituting (80) into (81), and solving, yields:

$$
\gamma=\left(1+r-\Omega\left(p_{K}\right)^{-\frac{1}{1-\alpha}} r^{-\frac{\alpha}{1-\alpha}}\right)^{\frac{\phi-\alpha}{\phi-1}}
$$

which is the analogue of equation (13) in the benchmark model.

The model is closed by the (discrete time) Euler equation for consumption:

$$
\gamma=[\beta(1+r)]^{\frac{1}{\sigma}}
$$

where $\beta$ is the discount factor. Equations (82) and (83) fully characterize the equilibrium.

\section{FIGURE 7}

Figure 7 provides a geometric representation for the case of logarithmic preferences and zero adjustment cost $\left(p_{K}=1\right)$. The SS curve is linear, with the slope $\beta^{-1}$. The DD curve is also positively sloped. In the case represented, the two curves cross twice, thereby implying that there are two BG equilibria featuring positive innovation and growth (points $X$ and $Y$ ).

Standard stability analysis is inappropriate for dynamic models with perfect foresight. It is possible, however, to analyze the expectational stability (E-stability) of the BG equilibria. E-stability is tested as follows. Set an arbitrary initial level for the expected interest rate $r^{e}$, and let agents choose their optimal savings plan according to (83). This implies a notional growth rate of consumption and capital, as determined by the SS curve. Next, firms take action. At the notional growth rate, there is a unique interest rate consistent with the no-arbitrage condition implied by (82), as shown by the DD curve. The composition of these two operations define a mapping from an expected to a realized interest rate:

$$
r_{t}=T\left(r_{t}^{e}\right)
$$


A perfect foresight BG equilibrium is a fixed point to the mapping, $r=T(r)$. After consumers have observed the realized interest rate, they update their expectations about next period's interest rate using adaptive learning, i.e.:

$$
r_{t+1}^{e}=r_{t}^{e}+\psi_{t}\left(r_{t}-r_{t}^{e}\right)
$$

where $\xi_{t}=\psi / t$. The sequence $\left\{\psi_{t}\right\}$ determine how sensitive the expectations are to past errors, and it is known as the gain sequence. (84) into (85) defines a dynamic system, whose stability can be analyzed by linearization techniques. In general, expectational stability occurs whenever $T^{\prime}(r)<1$, where $r$ is the steady-state interest rate. ${ }^{59}$

An inspection of Figure 7 shows the equilibrium $X$ to be E-stable, while the equilibrium $Y$ is not. Let $r_{X}^{e}$ and $r_{Y}^{e}$ denote two expected interest rates which are below the equilibria $X$ and $Y$, respectively. Then, in the case of the equilibrium $X, T\left(r_{X}^{e}\right)>r_{X}^{e}$, and the adaptive adjustment moves the economy towards the equilibrium, inducing convergence. In contrast, in the case of the equilibrium $Y, T\left(r_{Y}^{e}\right)<r_{Y}^{e}$, and the adaptive adjustment moves the economy away from the equilibrium, thereby inducing divergence.

In the case analyzed so far, only one BG is E-stable, and E-stabilty can be used as a selection criteria. It is possible, however, that multiple E-stable BG equilibria exist in the general model with convex adjustment costs.

\section{FIGURE 8}

Figure 8 describes a case with four steady-states, two of them being E-stable. Equilibria such as $X$ and $Z$ are E-stable (note that $T\left(r_{X}^{e}\right)>r_{X}^{e}$ and $T\left(r_{Z}^{e}\right)>r_{Z}^{e}$ ). Moreover, in the neighborhood of these equilibria, there exist stationary sunspot equilibria. In one such equilibrium, the economy switches stochastically between two points in the neighborhood of $X$ and $Z$, respectively, with switching probabilities given by a time-invariant transition probability matrix. The fact that both $X$ and $Z$ are E-stable is sufficient for any stationary sunspot equilibrium in their neighborhood to be E-stable in itself. ${ }^{60}$

We conclude that a modified version of the model of growth with expanding variety can generate endogenous fluctuations. The key assumptions are complementarity between capital goods and convex adjustment costs to capital. The former assumption guarantees the existence of multiple BG equilibria, around which sunspot equilibria can be constructed. The latter assumption guarantees that the sunspot equilibrium is expectationally stable, i.e., it can be learned through adaptive expectations.

\footnotetext{
${ }^{59}$ See Evans and Honkapohja (2001) for a state-of-art analysis of expectational indeterminacy.

${ }^{60}$ For general discussion of sunspot equilibria, see Azariadis and Guesnerie (1986), Grandmont (1986) and Azariadis (1993).
} 
The model assumes increasing returns to physical and knowledge capital. The reduced form representation of the final good technology is:

$$
Y=A^{\phi-\alpha} K_{F}^{\alpha}
$$

where $K_{F}=A x$ denotes aggregate capital used in intermediate production. Empirical estimates suggest that $\alpha \leq 0.4$, which implies that the lower bound to the output elasticity of knowledge to generate multiplicity is $\phi-\alpha=0.6$. Evans et al. (1998) provide a numerical example of an E-stable sunspot equilibrium, assuming $\phi=4$. Recent estimations from Porter and Stern (2000) using patent numbers report $\phi-\alpha$ to be around 0.1 , however. Therefore, the model seems to require somehow extreme parameters to generate endogenous fluctuations.

Augmenting the model with other accumulated assets, such as human capital, may help obtain the results under realistic parameter configurations. This is complicated by the presence of scale effects in the expanding variety model. However, in a recent paper, Dalgaard and Kreiner (2001) formulate a version of the model with human capital accumulation and without scale effects. In their model, both human capital (embodied knowledge) and technical change (disembodied knowledge) are used to produce final goods. The scale effect is avoided by congestion effects in the accumulation of human capital. An interesting feature of this model is that, unlike other recent models without scale effects, positive long-run growth in income per capita does not hinge on positive population growth.

\section{Conclusions}

In this chapter, we have surveyed recent contributions to growth theory inspired by Romer's (1990) expanding variety model. Key features of the theory are increasing returns through the introduction of new products that do not displace existing ones and the existence of monopoly rents providing an incentive for firms to undertake costly innovative investments. This model has had a tremendous impact on the literature, and we could only provide a partial review of its applications. Then, we decided to focus on a few major themes: trade and biased technical change, with their effects on growth and inequality, financial development, complementarity in the process of innovation and endogenous fluctuations.

While only being a limited selection, these applications give a sense of the success of the model in providing a tractable framework for analyzing a wide array of issues in economic growth. In fact, we have shown how the model can incorporate a number of general equilibrium effects that are fundamental in the analysis of trade, wage inequality, cross-country productivity differences and other topics. Further, while the original model has linear AK-dynamics, we have surveyed recent generalizations featuring richer dynamics, which can potentially be applied to the study of financial development and innovations waves. Given its longevity, flexibility and simplicity, we are convinced that the growth model with horizontal innovation will continue to be useful in future research. 


\section{REFERENCES}

[1] Acemoglu, D. (1998), "Why Do New Technologies Complement Skills? Directed Technical Change and Wage Inequality" Quarterly Journal of Economics 113, 1055-1090.

[2] Acemoglu, D. (2002), "Directed Technical Change," Review of Economic Studies, 69, pp. 781-809.

[3] Acemoglu, D. (2003a), "Patterns of Skill Premia," Review of Economic Studies, 70, pp. 199-230.

[4] Acemoglu, D. (2003b), "Labor- and Capital-Augmenting Technical Change," Journal of the European Economic Association 1, 1-37.

[5] Acemoglu, D. and F. Zilibotti (2001), "Productivity Differences," Quarterly Journal of Economics 116, 563-606.

[6] Acemoglu, D. and F. Zilibotti (1997), "Was Prometheus Unbounded by Chance? Risk, Diversification and Growth", Journal of Political Economy, 105, 710-751.

[7] Aghion, P. and P. Howitt (1998), Endogenous Growth Theory, (MIT Press, Cambridge).

[8] Aghion, P. and P. Howitt (1992), "A Model of Growth through Creative Destruction," Econometrica, 60, 2, 323-351.

[9] Antras, P. (2004), "Is the U.S. Aggregate Production Function Cobb-Douglas? New Estimates of the Elasticity of Substitution," Contributions to Macroeconomics, Vol. 4, No. 1.

[10] Arrow, K.J. (1962), "The Economic Implications of Learning-by-Doing," Review of Economic Studies 29,1, 155-173.

[11] Atkinson, A.B. and J.E. Stiglitz (1969). "A New View of Technological Change," Economic Journal, 573-578.

[12] Azariadis, C. (1993), Intertemporal Macroeconomics (Blackwell Publishers).

[13] Azariadis, C. and R. Guesnerie (1986), "Sunspots and Cycles," Review of Economic Studies, 53, 725-737.

[14] Barro, R.J. and X. Sala-i-Martin (1995), Economic Growth (McGraw-Hill).

[15] Barro, R.J. and X. Sala-i-Martin (1997), "Technological Diffusion, Convergence, and Growth", Journal of Economic Growth, 2, 1-26.

[16] Benassy, J.-P. (1998), "Is There Always Too Little Research in Endogenous Growth with Expanding Product Variety?" European Economic Review 42, 61-69. 
[17] Bencivenga, V. and B. Smith (1991), "Financial Intermediation and Endogenous Growth." Review of Economic Studies 58, 195-209.

[18] Borjas, G.J., R.B. Freeman and L.F. Katz (1997), "How much do immigration and trade affect labor market outcomes", Brookings Papers on Economic Activity, $1-67$.

[19] Braudel, F. (1979), Civilization and Capitalism. (Harper and Row, New York).

[20] Caselli, F., G. Esquivel and F. Lefort (1996), "Reopening the Convergence Debate: A New Look at Cross-Country Growth Empirics" Journal of Economic Growth, $1,363-389$.

[21] Caselli, F. and J. Coleman (2000), "The World Technology Frontier," NBER Working Paper 7904.

[22] Cetorelli, N. (2002), "Could Prometheus Be Bound Again? A Contribution to the Convergence Controversy", Journal of Economic Dynamics and Control 27, 29-50.

[23] Ciccone, A. and K. Matsuyama (1999), "Efficiency and Equilibrium with Dynamic Increasing Returns Due to Demand Complementarities," Econometrica, 67, 499525 .

[24] Ciccone, A. and K. Matsuyama (1996), "Start-up Costs and Pecuniary Externalities as Barriers to Economic Development," Journal of Development Economics 49, 33-59.

[25] Cohen, W.M. and R.C. Levin (1989), "Empirical Studies of Innovation and Market Structure," in: Handbook of Industrial Organization, Vol II, 1059-1107 (Elsevier Science Publishers).

[26] Cooper, R.W. and A. John (1988), "Coordinating Coordination Failures in Keynesian Models," Quarterly Journal of Economics, 103, 441-463.

[27] Dalgaard, C.-J. and C.T. Kreiner (2001), "Is Declining Productivity Inevitable?" Journal of Economic Growth, vol. 6, 187-203.

[28] Dinopoulos, E. and P. Segerstrom (1999), "A Schumpeterian Model of Protection and Relative Wages," American Economic Review 89, 450-472.

[29] Dinopoulos, E. and P. Segerstrom (2003), "A Theory of North-South Trade and Globalization", mimeo, Stockholm School of Economics.

[30] Devereux, M.B. and B.J. Lapham (1994), "The Stability of Economic Integration and Endogenous Growth" Quarterly Journal of Economics, 109, 299-305.

[31] DeVries, J. (1990), The Economy of Europe in an Age of Crisis; 1600-1750 (Cambridge University Press, Cambridge). 
[32] Dixit, A.K. and J.E. Stiglitz (1977), "Monopolistic Competition and Optimum Product Diversity," American Economic Review 67,3, 297-308.

[33] Diwan, I. and D. Rodrik (1991), "Patents, Appropriate Technology, and NorthSouth Trade," Journal of International Economics 30, 27-48.

[34] Dornbusch, R., S. Fischer and P.A. Samuelson, (1977), "A Continuum Ricardian Model of Comparative Advantage, Trade and Payments" American Economic Review $67,823-839$.

[35] Epifani, P. and G. Gancia (2002), "The Skill Bias of World Trade" IIES Seminar Paper 707.

[36] Ethier, W.J. (1982), "National and International Returns to Scale in the Modern Theory of International Trade," American Economic Review, Vol.72 No.3, 389-405.

[37] Evans, G., S. Honkapojha and P. Romer (1998), "Growth Cycles," American Economic Review, Vol. 88, No. 3, 495-515

[38] Evans, G., and S. Honkapohja, (2001), Learning and Expectations in Macroeconomics, (Princeton University Press).

[39] Francois, P. and H. Lloyd-Ellis (2003), "Animal Spirits Through Creative Destruction" American Economic Review, 93, 530 - 550.

[40] Funke, M. and H. Strulik (2000), "On Endogenous Growth with Physical Capital, Human Capital and Product Variety" European Economic Review, 44, 491-515.

[41] Gancia, G. (2003), "Globalization, Divergence and Stagnation" IIES Seminar Paper 720 .

[42] Grandmont, J.-M. (1986), "Periodic and Aperiodic Behavior in Discrete OneDimensional Dynamical System", in: W. Hildenbrand and A. Mas-Colell, eds., Contributions to Mathematical Economics: In Honor of Gerard Debreu (Elsevier Science Publishers).

[43] Greenwood, J. and B. Jovanovic (1990), "Financial Development, Growth and the Distribution of Income." Journal of Political Economy 98 , 1067-1107.

[44] Griliches, Z. and J. Schmookler (1963), "Inventing and Maximizing" American Economic Review 53, 725-729.

[45] Grossman, G. and E. Helpman (1989), "Product Development and International Trade" Journal of Political Economy 97, 1261-83.

[46] Grossman, G. and E. Helpman (1991a), "Innovation and Growth in the World Economy" (MIT Press, Cambridge).

[47] Grossman, G. and E. Helpman (1991b), "Endogenous Product Cycles" Economic Journal 101, 1214-1229. 
[48] Grossman, G. and E. Lai (2004), "International Protection of Intellectual Property" American Economic Review, forthcoming.

[49] Habakkuk, H.J. (1962), American and British Technology in the Nineteenth Century: Search for Labor Saving Inventions (Cambridge University Press).

[50] Hall, R. and C.I. Jones (1999), "Why Do Some Countries Produce So Much More Output Per Workers Than Others?" Quarterly Journal of Economics 114, 83-116.

[51] Hamermesh, D.S. (1993), Labor Demand (Princeton University Press).

[52] Helpman, E. (1993), "Innovation, Imitation and Intellectual Property Rights," Econometrica 61, 1247-1280.

[53] Helpman, E. (1998), General Purpose Technology and Economic Growth (MIT Press, Canbridge).

[54] Helpman, E. and P. Krugman (1985), Market Structure and Foreign Trade (MIT Press, Cambridge).

[55] Hicks, J. (1932), The Theory of Wages (Macmillan, London).

[56] Imbs, J. and R. Wacziarg (2003), "Stages of Diversification" American Economic Review, 93, 63-86.

[57] Jones, C.I. (1995), "R\&D-Based Models of Economic Growth," Journal of Political Economy, 103, August, 759-784.

[58] Jones, C.I. (1999), "Growth: With or Without Scale Effects," American Economic Review, Papers and Proceedings, 107.

[59] Jones, C.I. (2001), "Was the Industrial Revolution Inevitable? Economic Growth Over the Very Long Run", Advances in Macroeconomics, Vol. 1: No. 2, Article 1.

[60] Judd, K.L. (1985), "On the Performance of Patents" Econometrica 53, 3, 567-585.

[61] Kalemli-Ozcan, S., B.E. Sorensen and O. Yosha (2001), "Economic integration, industrial specialization, and the asymmetry of macroeconomic fluctuations" Journal of International Economics, 55, 107-137.

[62] Kalemli-Ozcan, S., B.E. Sorensen and O. Yosha (2003), "Risk sharing and industrial specialization: Regional and international evidence" American Economic Review, 93, 903-918.

[63] Kennedy, C. (1964), "Induced Bias in Innovation and the Theory of Distribution," Economic Journal, 541-547.

[64] Klenow, P.J. (1996), "Industry Innovation: Where and Why" Carnegie-Rochester Conference Series on Public Policy 44, 125-150. 
[65] Klenow, P.J. and A. Rodriguez-Clare (1997), "The Neoclassical Revival in Growth Economics: Has It Gone Too far?" NBER Macroeconomics Annual, 73-102.

[66] Krugman, P. (1991), "Increasing Returns and Economic Geography," Journal of Political Economy 99, 483-499.

[67] Krugman, P. and A. Venables (1995), "Globalization and the Inequality of Nations," Quarterly Journal of Economics, 110, 857-880.

[68] Krusell, P., L. Ohanian, V. Rios-Rull and G. Violante (2000), "Capital Skill Complementarity and Inequality," Econometrica, 1029-1053.

[69] Kwan, F.Y.K. and E.L.C. Lai (2003), "Intellectual Property Rights Protection and Endogenous Economic Growth," Journal of Economic Dynamics and Control, 27, 853-873.

[70] Lai, E.L.C. (1998), "International Intellectual Property Rights Protection and the Rate of Product Innovation," Journal of Development Economics 55, 133-153.

[71] Lai, E.L.C. and L.D. Qiu (2003), "The North's intellectual property rights standard for the South?" Journal of International Economics 59, 183-209.

[72] Levhari, D. and E. Sheshinski (1969), "A Theorem on Returns to Scale and SteadyState Growth," Journal of Political Economy 77, 60-65.

[73] Martin, P. and H. Rey (2000), "Financial Integration and Asset Returns", European Economic Review, 44, 1327-1350.

[74] Martin, P. and H. Rey (2001), "Financial Super-Markets: Size Matters for Asset Trade", NBER Working Paper 8476.

[75] Martin, P. and H. Rey (2002), "Financial Globalization and Emerging Markets: With or Without Crash?", NBER Working Paper 9288.

[76] Matsuyama, K. (1995), "Complementarities and Cumulative Processes in Models of Monopolistic Competition," Journal of Economic Literature 33, 701-729.

[77] Matsuyama, K. (1996), "Why Are There Rich and Poor Countries? SymmetryBreaking in the World Economy," Journal of the Japanese and International Economies 10, 419-439.

[78] Matsuyama, K. (1997), "Complementarity, Instability and Multiplicity," The Japanese Economic Review 48, 240-266.

[79] Matsuyama, K. (1999), "Growing Through Cycles," Econometrica 67, 335-348.

[80] Matsuyama, K. (2001), "Growing Through Cycles in an Infinitely Lived Agent Economy," Journal of Economic Theory 100, 220-234. 
[81] Murphy, K.M., A. Shleifer and R.W. Vishny (1989), "Industrialization and the Big Push," Quarterly Journal of Economics, 106, 2, 503-530.

[82] Neary, P. (2003), "Globalisation and market structure," Journal of the European Economic Association 1, 245-271.

[83] Nordhaus, W.D. (1969a), "An Economic Theory of Technological Change" American Economic Review 59,2 18-28.

[84] Nordhaus, W.D. (1969b), Invention, Growth and Welfare: A Theoretical Treatment of Technological Change (MIT Press, Cambridge).

[85] North, D. and R.P. Thomas (1973), The Rise of the Western World: A New Economic History (Cambridge University Press).

[86] Parente, S.L. and E.C. Prescott (1994), "Barriers to Technology Adoption and Development," Journal of Political Economy, 102, 298-321.

[87] Porter, M.E. and S. Stern (2000), "Measuring the "ideas" Production Function: Evidence from International Patent Output", NBER Working Paper 7891.

[88] Prescott, E.C. (1998), "Needed: A Theory of Total Factor Productivity," International Economic Review, 39 , 525-553.

[89] Ramey, G. and V. Ramey (1995), "Cross-Country Evidence of the Link between Volatility and Growth" American Economic Review 85, 1138-51.

[90] Rebelo, S. (1991), "Long-Run Policy Analysis and Long-Run Growth," Journal of Political Economy 99 (3), 500-521.

[91] Rivera-Batiz, L. and P. Romer (1991a), "Economic Integration and Endogenous Growth" Quarterly Journal of Economics 106, 531-55.

[92] Rivera-Batiz, L. and P. Romer (1991b), "International Trade with Endogenous Technological Change" European Economic Review 35, 971-1004.

[93] Rodriguez-Clare, A. (1996), "The Division of Labor and Economic Development," Journal of Development Economics, 49, 3-32.

[94] Romer, P. (1986), "Increasing Returns and Long-Run Growth" Journal of Political Economy 94, 1002-1037.

[95] Romer, P. (1987), "Growth Based on Increasing Returns due to Specialization", American Economic Review, 77, 56-62.

[96] Romer, P. (1990), "Endogenous Technological Change," Journal of Political Economy $98,71-102$.

[97] Romer, P. (1994), "New Goods, Old Theory and the Welfare Costs of Trade Restrictions," Journal of Development Economics, 43, 5-77. 
[98] Rosenberg, N. (1976), Perspectives on Technology (Cambridge University Press).

[99] Samuelson, P. (1965), "A Theory of Induced Innovations along Kennedy-Weisacker Lines" Review of Economics and Statistics, 444-464.

[100] Schmookler, J. (1966),. Invention and Economic Growth (Harvard University Press).

[101] Schumpeter, J.A. (1942), Capitalism, Socialism and Democracy (Harper, New York).

[102] Segerstrom, P.S., T.C.A. Anant and E. Dinopoulos (1990), "A Schumpeterian Model of the Product Life Cycle," American Economic Review 80, 1077-1091.

[103] Shell, K. (1973), "Inventive Activity, Industrial Organization and Economic Growth" in: J.A. Mirrels and N.H. Stern, eds., Models of Economic Growth, New York, Wiley.

[104] Shleifer, A. (1986),. "Implementation Cycles," Journal of Political Economy, 94, 1163-1190.

[105] Solow, R.M. (1956), "A Contribution to the Theory of Economic Growth" Quarterly Journal of Economics, 70, 65-94.

[106] Spence, M. (1976), "Product selection, Fixed Costs, and Monopolistic Competition," Review of Economic Studies 43, 217-235.

[107] Stiglitz, J.E. (1970), "Factor Price Equalization in a Dynamic Economy," Journal of Political Economy, 78, 456-488.

[108] Swan, T.W. (1956), "Economic Growth and Capital Accumulation," Economic Record.32, 334-361.

[109] Thoenig M. and T. Verdier (2003), "Trade Induced Technical Bias and Wage Inequalities: A Theory of Defensive Innovations," American Economic Review, 93, 709-728.

[110] Ventura, J. (1997), "Growth and Interdependence," Quarterly Journal of Economics, $112,57-84$.

[111] Vernon, R. (1966), "International Investment and International Trade in ProductCycle," Quarterly Journal of Economics 80, 190-207.

[112] Wood, A. (1994), North-South Trade, Employment and Inequality: Changing Fortunes in a Skill Driven World (Clarendon Press, Oxford).

[113] Yang, G. and K.E. Maskus (2001), "Intellectual property rights, licensing and innovation in an endogenous product-cycle model" Journal of International Economics 53, 169-187. 
[114] Young, A. (1928), "Increasing Returns and Economic Progress" Economic Journal 38 (152) 527-542.

[115] Young, A. (1991), "Learning by Doing and the Dynamic effects of International Trade" Quarterly Journal of Economics, 106, 369-406.

[116] Young, A. (1993), "Substitution and Complementarity in Endogenous Innovation," Quarterly Journal of Economics, 108, 775-807.

[117] Young, A. (1995), "The Tyranny of Numbers: Confronting the Statistical Realities o the East Asian Growth Experience," Quarterly Journal of Economics, 110, 641680.

[118] Xie, D. (1998), "An Endogenous Growth Model with Expanding Ranges of Consumer Goods and of Producer Durables," International Economic Review, 39 43960 .

[119] Zilibotti, F. (1994), "Endogenous Growth and Intermediation in an Archipelago Economy." Economic Journal 104, 462-473.

[120] Zilibotti, F. (1995), "A Rostovian Model of endogenous growth and underdevelopment traps," European Economic Review, 39, 1569-1602. 


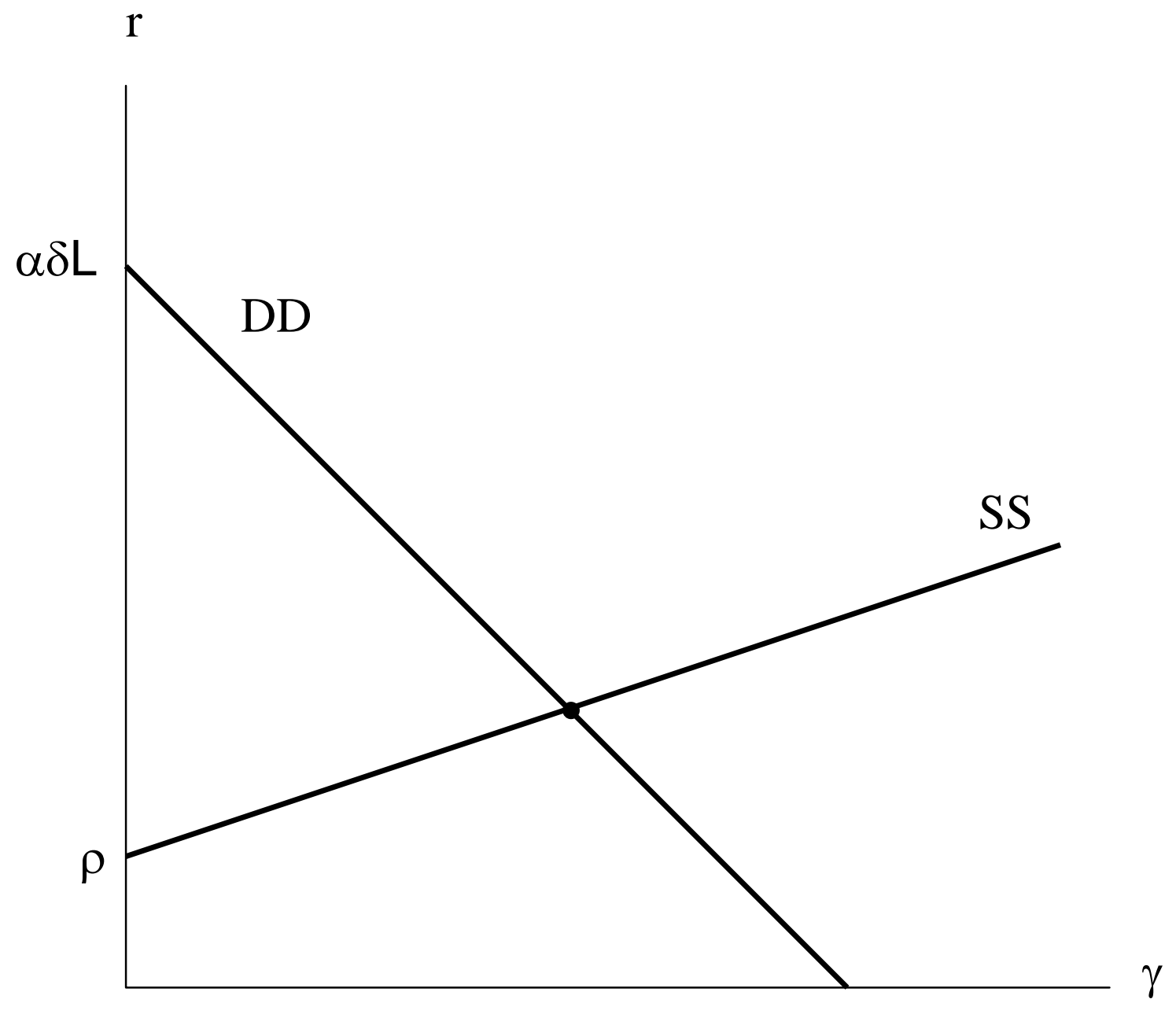

FIGURE 1 


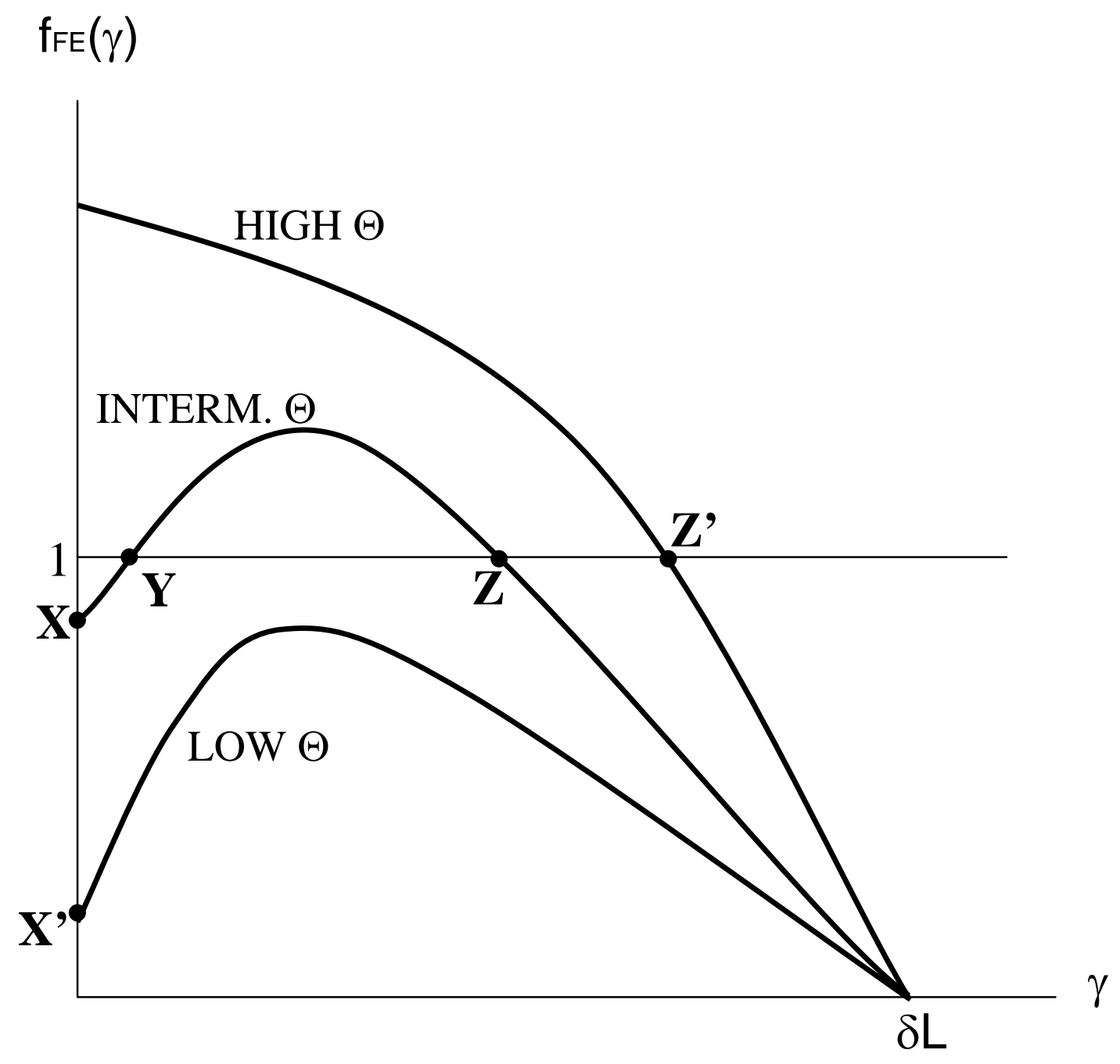

FIGURE 2 


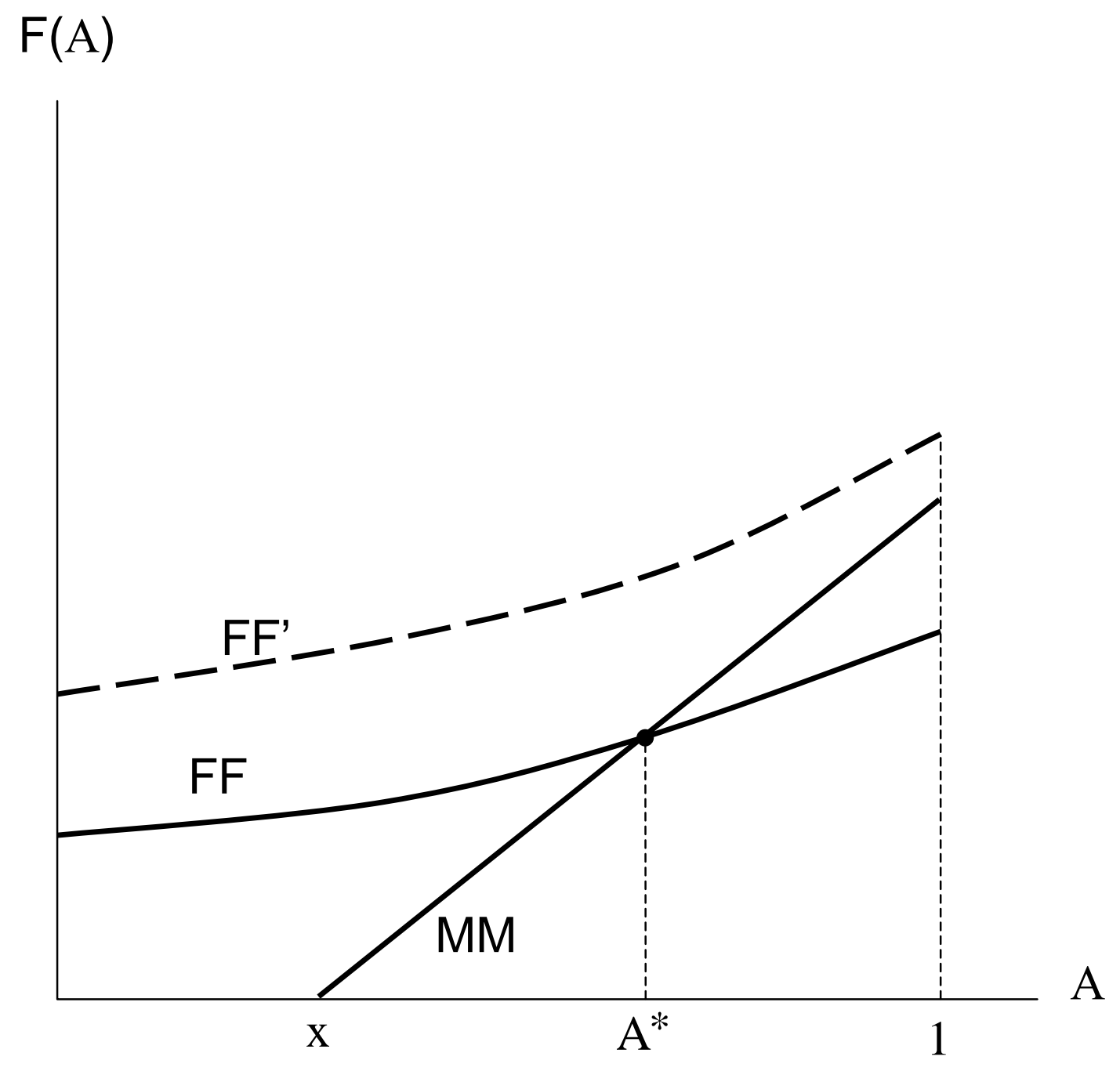

FIGURE 3 


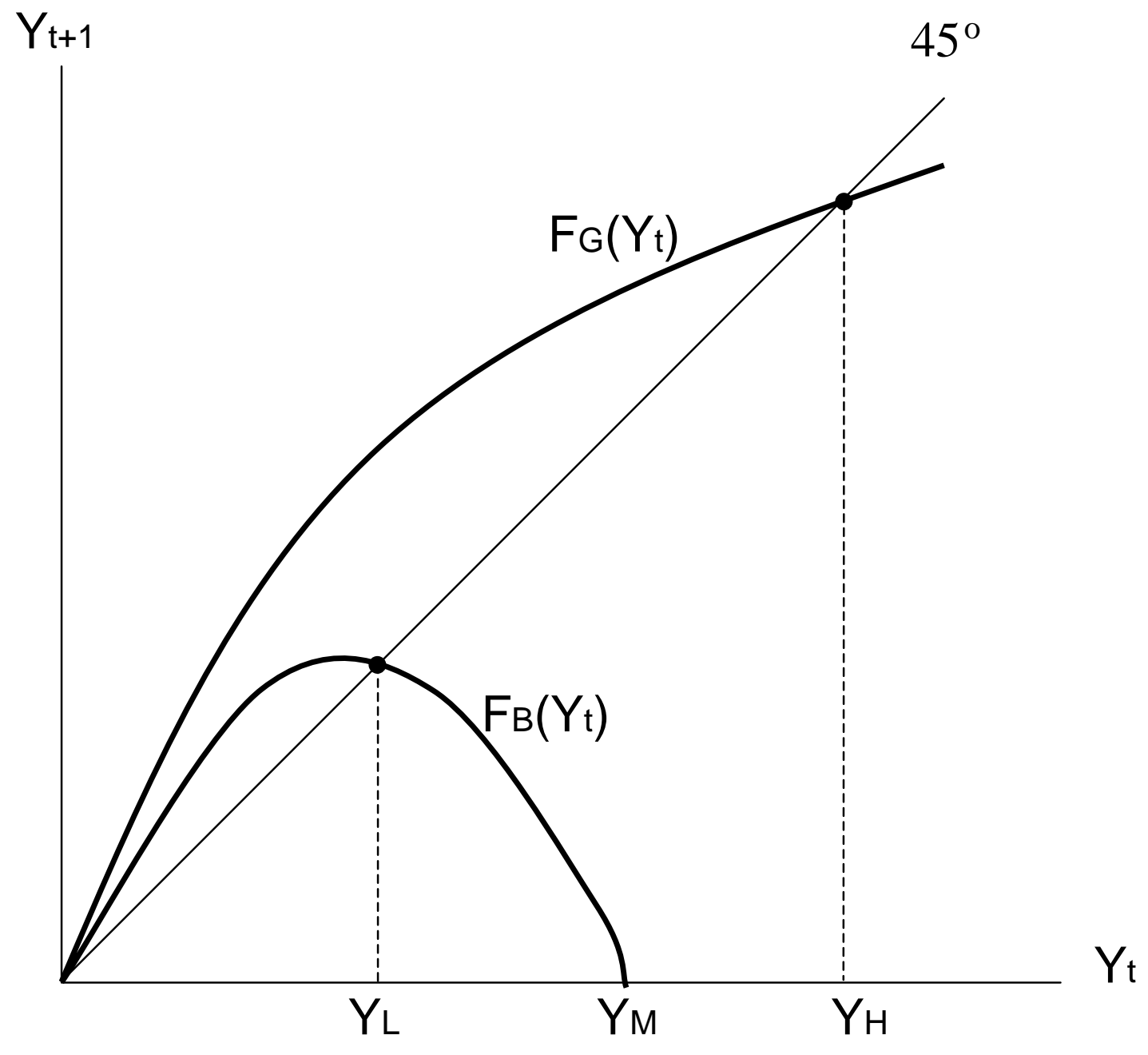

FIGURE 4 


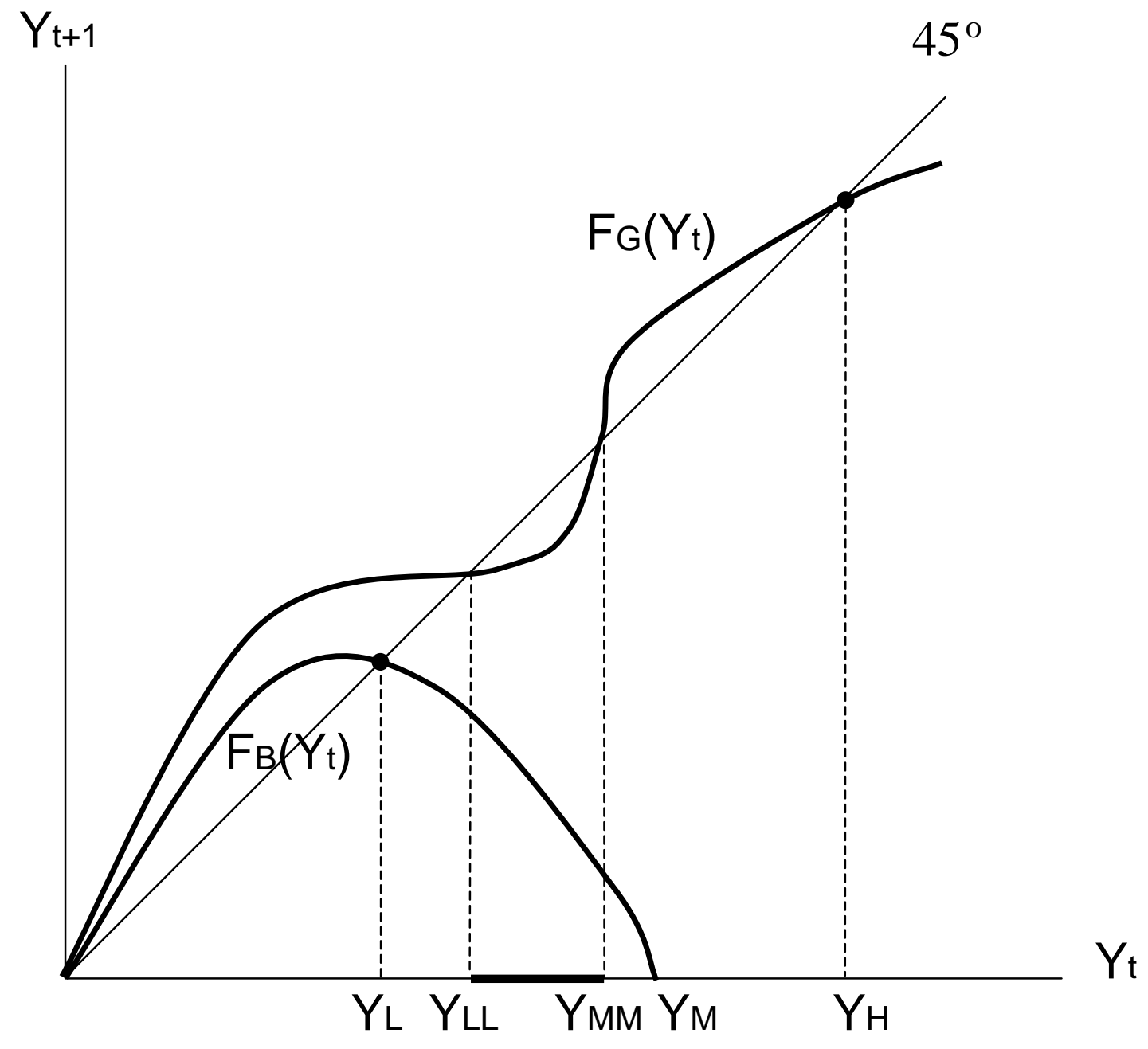

FIGURE 5 


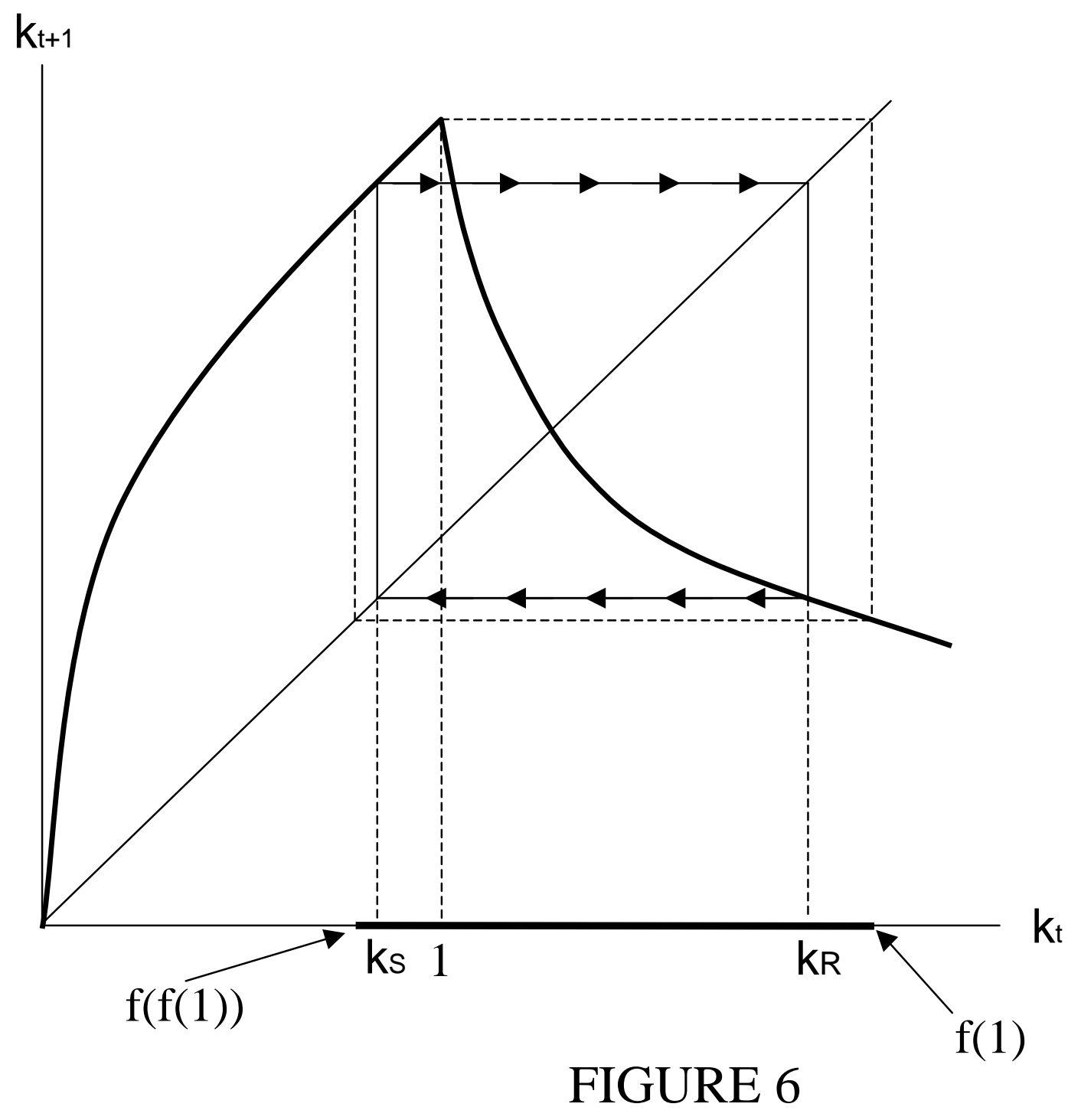




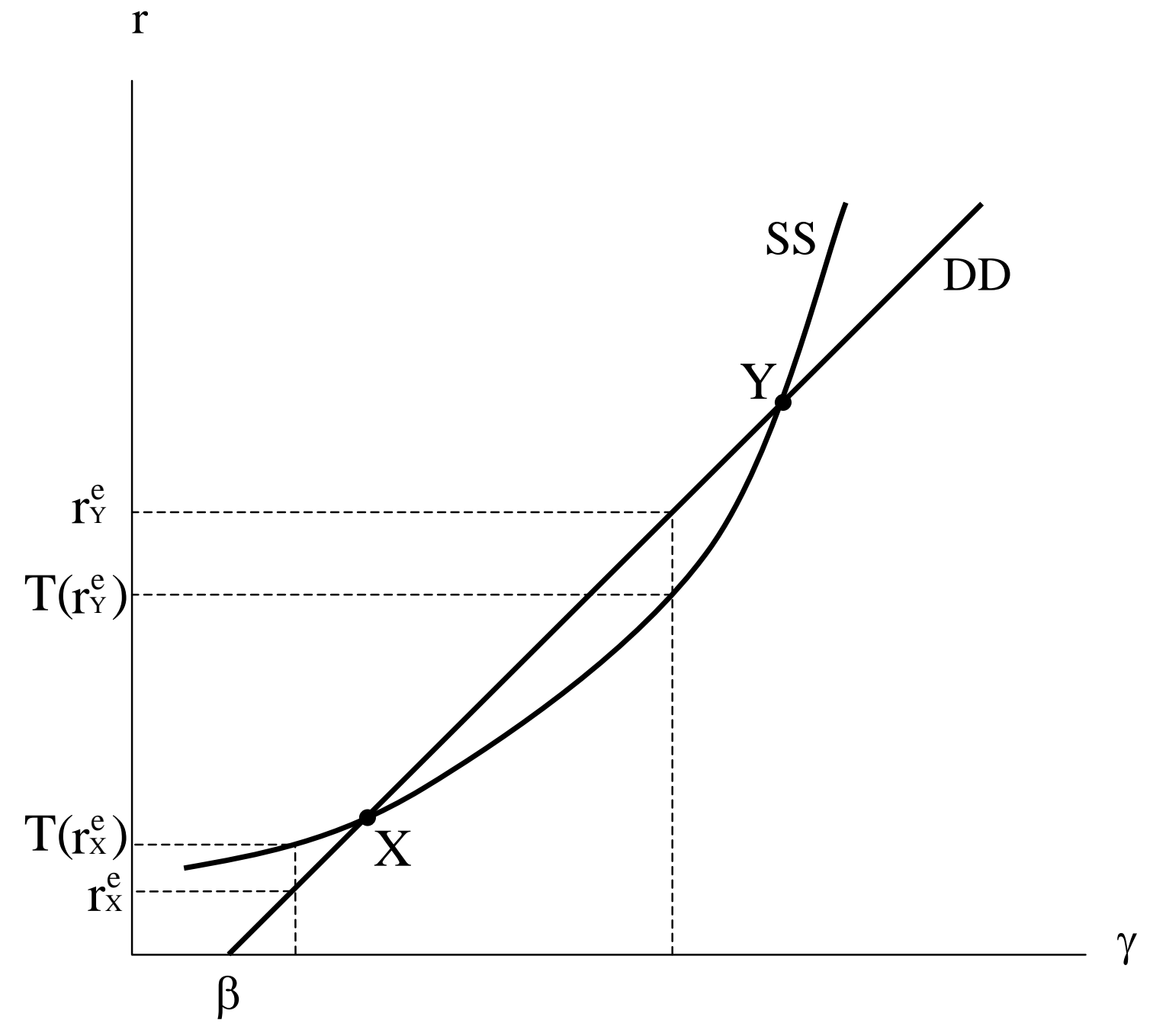

FIGURE 7 


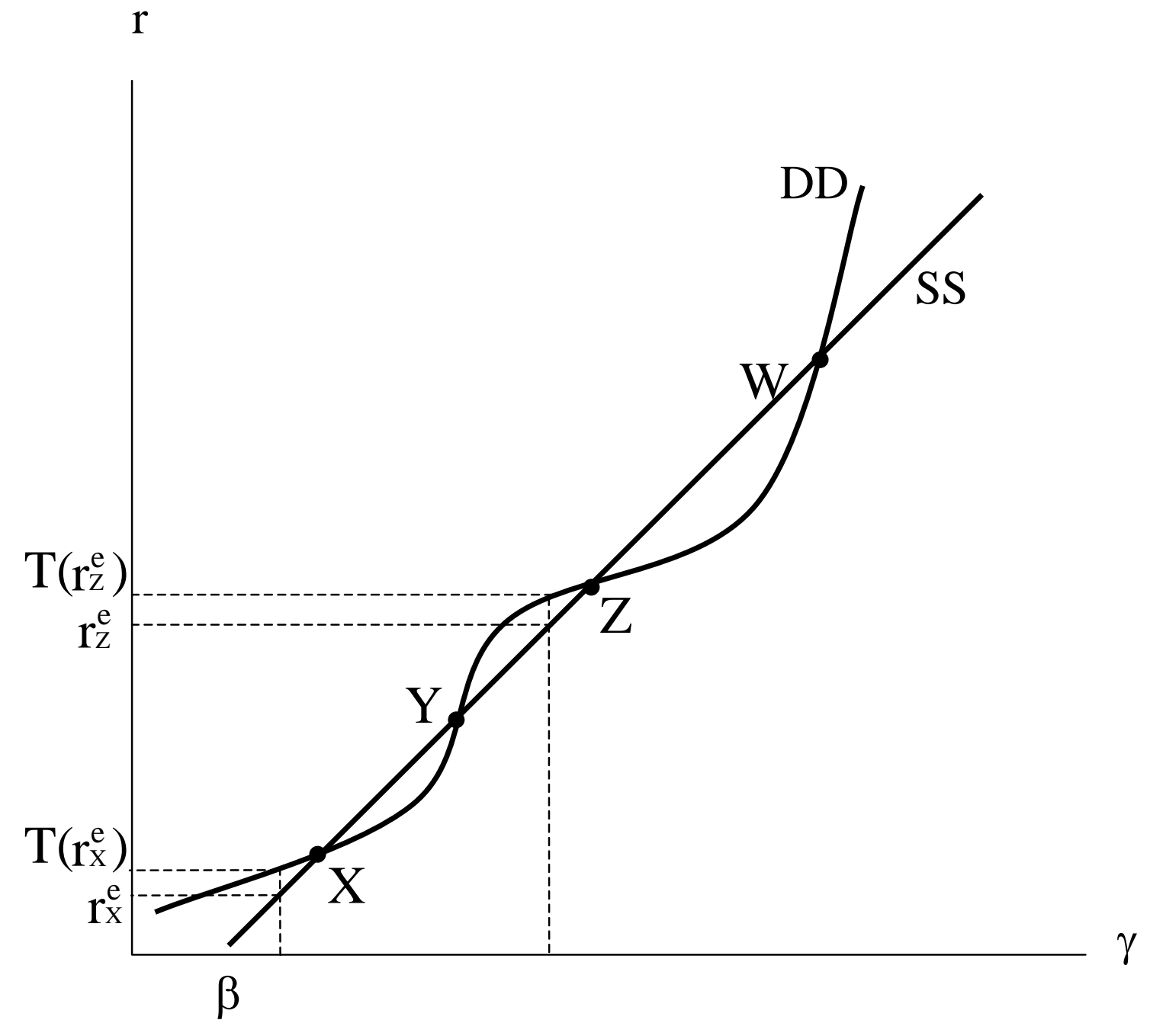

FIGURE 8 